\title{
DECLARACIÓN DE LA DISCAPACIDAD Y BENEFICIOS SOCIALES EN LAS PERSONAS CON TEA (TRASTORNOS DEL ESPECTRO AUTISTA)
}

\author{
LA DÉCLARATION SUR LE HANDICAP ET LES \\ AVANTAGES SOCIALES EN FAVEUR DES PERSONNES \\ AVEC TSA (TROUBLES DU SPECTRE AUTISTIQUE)
}

\author{
Ramón SOLER BELDA ${ }^{1}$
}

Recibido: 03/05/2020

Aceptado: 07/06/2020

\begin{abstract}
SUMARIO: Introducción. I. Las incapacidades desde el punto de vista juridico. 1. Derecho y desigualdad. 2. El recorrido en busca de la inclusión. 3. La protección jurídica de las personas con discapacidad. 4. Proceso de modificación de la capacidad. II. La valoración jurídica de la discapacidad psíquica. III. Ayudas sociales a las disfuncionalidades psiquicas. 1. La protección de la discapacidad en general. 2. Descripción de las ayudas sociales a la discapacidad. IV. Ayudas tributarias a la discapacidad. 1. Ayudas sobre tributos estatales. 2. Minoraciones por aportación en los tributos estatales. 3. Ayudas Autonómicas. 4. Ayudas Municipales. 5. Beneficios fiscales para la contratación laboral en personas con incapacidad. 6. Beneficios en el impuesto de Transmisiones Patrimoniales, AJD y OS. 7. Beneficios para la incapacidad a efectos del Impuesto sobre el Patrimonio. 8. Beneficios a efectos del Impuesto de Sucesiones y Deducciones para personas con discapacidad. 9. Beneficios en el IVA por motivo de la incapacidad. 10. Beneficio a efecto de las leyes de Impuestos Especiales. V. Ayudas en el ámbito laboral. 1. Reserva de empleos públicos y privados para personas con discapacidad. 2. Reducción de cuotas de la Seguridad Social. 3. Ayudas a las empresas privadas para adaptación de los puestos de trabajo. 4. Creación de centros especiales de empleo. 5. Centro Ocupacional. 6. Ayudas al autoempleo. VI. Conclusiones.
\end{abstract}

RÉSUMÉ: Introduction. I. Les handicap du point de vue juridique. 1. Droit et inégalité. 2. Le voyage à la recherche de l'inclusion. 3. La protection juridique des personnes handicapées. 4. Processus de modification de capacité. II. L'évaluation juridique du handicap psychique. III. Aide sociale pour les dysfonctionnalités psychiques. 1. Protection du handicap en général. 2. Description de l'aide sociale pour le handicap. IV. Aide fiscale pour les handicapés. 1. Aide sur les impôts d'État. 2. réductions des impôts d’État. 3. Aide régionales. 4. Aide municipales. 5. Avantages fiscaux pour l'embauche de personnes handicapées. 5.1. Reconnaissance de la discrimination sur le lieu de travail. 5.2. Augmentation du personnel des travailleurs handicapés. 5.3. Réduction des modules dans l'embauche de personnes handicapées. 6. Avantages de la taxe sur les transferts de biens. 7. Prestations d'invalidité aux fins d'impôt de solidarité sur la fortune. 8. Prestations aux fins de l'impôt sur les successions et des déductions pour les personnes handicapées. 9. Prestations de TVA pour invalidité. 10. Prestation au sens des lois fiscales spéciales. V. Aide dans le domaine du travail. 1. Réserver des emplois publics et privés aux personnes handicapées. 2. Réduction des cotisations de sécurité sociale. 3. Aide aux entreprises privées pour adapter leurs emplois. 4. Création de centres spéciaux pour l'emploi. 5. Etablissements et Services d’Aide par le Travail. 6. Aide au travail indépendant. VI. Conclusions.

Resumen: El procedimiento de modificación de la capacidad civil, puede venir apoyada por una serie de consecuencias administrativas que benefician a aquellas personas que manifiestan TEA. Comentar como se obtiene la discapacidad, estructurar las ayudas y conocer la forma de obtención es el objetivo de este trabajo.

\footnotetext{
${ }^{1}$ Abogado y doctor en Derecho. Profesor Sustituto Interino de Derecho Civil en la UJA.
} 
Palabras Clave: Espectro autista. discapacidad, ayudas sociales, económicas, laborales y tributarias

Résumé: La procédure de modification de la capacité civile peut être soutenue par une série de conséquences administratives qui profitent à ceux qui manifestent un TSA. Discuter de la manière dont le handicap est obtenu, structurer l'aide et savoir comment l'obtenir est l'objectif de ce travail.

Mots-clés: Spectre autistique. L’invalidite. Aides sociaux, économiques, de travail et fiscales.

\section{INTRODUCCIÓN}

La intención de este artículo es que sirva de guía para quienes decidan afrontar la realización del título propio de la UJA sobre “Trastornos del Espectro Autista" dirigido por la profesora y amiga Beatriz Montes, a quien agradezco que haya pensado en mí para impartir esta materia, donde se incluye una asignatura sobre esta materia. También pretende ser un revulsivo para todos aquellos desconocedores, tanto del problema, como de las propuestas que se han ido generando a lo largo del tiempo para buscar la ayuda y la inclusión de una parte de la sociedad que puede oscilar en torno al $1 \%$ de la población ${ }^{2}$, siendo un porcentaje que crece en la medida en que se cambian los criterios de diagnóstico y cada vez se clasifican más personas dentro de este ámbito. En la actualidad existe un alto porcentaje de nuestra sociedad que requiere un trato especial y la concienciación en la materia es cada vez mayor; en este marco de actuaciones, la discapacidad esta entre los Objetivos de Desarrollo Sostenible que ha establecido una agenda para 2030 que los incluye como uno de los problemas a solucionar ${ }^{3}$. Una solución que va más allá de dar una ayuda y que está en la línea de la inclusión posible de estas personas. Estando incluidos en estos objetivos algunos tipos de autismo entre los que cuentan con posibilidades reales de ser integrados en la sociedad.

No es intención de este trabajo el profundizar en las cuestiones de tipo médico, educativo ${ }^{4}$, psicológico o sociológico del espectro autista, o los fenómenos derivados, como el asperger. Pero es necesario insistir en la necesidad que tienen las personas vinculadas a este tipo de trastornos, de organizarse, tanto para su cuidado y mejora, como para el conocimiento de aquello que mejor le pueda convenir en su vida cotidiana.

Indudablemente estamos ante un problema que requiere un planteamiento sanitario que supone una serie de protocolos de actuación y de revisiones en la investigación que ha concluido en la creación de una guía de buenas prácticas para su tratamiento, donde se recogen diseños metodológicos en las investigaciones realizadas y las revisiones basadas en la evidencia, donde se ha avanzado enormemente en las

\footnotetext{
2 LOZANO MARTINES, J: “Trastornos del Espectro Autista”; Padres y Maestros; no 31; Marzo-abril; 2010; Págs. 21 a 26

3 COLECTIVO: Objetivos de desarrollo sostenible y promoción de los derechos de las personas con discapacidad; Ediciones Cinca; 2018.

${ }^{4}$ Interesante algunos comentarios en revistas sobre la sensación de quienes parecen estos trastornos: FERNANDEZ PRADA, M: “comprender los trastornos del espectro autista”; Calidad. Boletín Informativo de la Consejería de Calidad de Asturias; nº 5; 2013; págs. 8 a 10.
} 
últimas décadas ${ }^{5}$, clasificándose los diferentes cuadros en los que se reconoce estas dolencias ${ }^{6}$.

Tal vez sea desde la visión del profesional de la educación donde se comenzó a entender que la mejor forma de tratar este tipo de trastornos era intentando individualizar los mismos ${ }^{7}$, al menos desde el punto de vista de la mejora en la inclusión de las personas que los sufrían, que en ocasiones llegaban hasta el acoso ${ }^{8}$. Son muchos los trabajos que han incidido en esta materia, que aportan luz a entender el desarrollo en la búsqueda de soluciones individualizadas ${ }^{9}$ para este tipo de alumnos. Trabajos en los que se trata de la necesidad de un conocimiento específico ${ }^{10}$, la conveniencia de la escolarización ${ }^{11}$, generalmente de una forma inclusiva ${ }^{12}$, para integrar a estos alumnos.

Como se aprecia a lo largo de este estudio, lo fundamental es la clasificación dentro de la discapacidad. Es posible que muchos de quienes manifiestan TEA no tengan opción a realizar las actividades para las que se presta ayuda o carezcan de interés en algunas de las cuestiones que aquí se plantean. Pero debido al amplio espectro al que se dirigen las mismas, es necesario tener en cuenta todas las situaciones. Existen trabajos de más envergadura a los que en muchos casos me remito, para quien esté interesado en conocer más sobre algunos aspectos concretos.

\section{LAS INCAPACIDADES DESDE EL PUNTO DE VISTA JURIDICO.}

\subsection{Derecho y desigualdad.}

Frente a otras disciplinas científicas de carácter más personalizado, como la medicina, la educación o la psicología; el derecho comparte con otras ramas de la ciencia su vocación de igualdad: ante determinados fenómenos, el legislador siempre debe actual de la misma forma, la legislación ha de ser la misma y tratar a todos los sujetos a los que se dirige la norma, de manera similar. Tal vez este haya sido uno de los inconvenientes para avanzar en campos, donde esa supuesta situación de igualdad no

\footnotetext{
5 VARIOS AUTORES: “Guía de buenas prácticas para el tratamiento de los trastornos del espectro autista; Revista de Neurología; nº 43; 2006; Págs. 435 a 438.

${ }^{6}$ RUIZ LAZARO, P.M; POSADA DE PAZ, M; HIJANO BANDERA, F: “Trastornos del Espectro Autista. Detección precoz, herramientas de cribado; Revista Pediátrica de Atención Primaria; $\mathrm{n}^{\circ} 11$; 2009; Suplemento 17; Págs. 381-397.

7 JIMENEZ MARTINEZ, F: "Reflexiones y dudas en torno a los trastornos del espectro autista y su educación”; Educatio Siglo XXI; Vol. 30; nº 1; 2012; Págs. 187.214.

${ }^{8}$ GARCIA PORRAS, D: Guía para prevenir el acoso escolar por razón de discapacidad; CERMI; 2007.

${ }^{9}$ BRUM, J.M.; OLIVES, S.; AIXANDRI, N: “Trabajos en red. La necesaria respuesta asistencial a la complejidad de los TEA”; Maremagnum; Págs. 111 a 120. Esta publicación especializada es fuente de muchos artículos dedicados al TEA https://dialnet.unirioja.es/servlet/revista?codigo=12358, no solo desde el aspecto educativo, también desde la psiquiatría, psicología, y aporta estrategias para mejorar la comunicación y la educación de este tipo de personas. Se reseñan algunos artículos más de la misma, si bien es interesante su conocimiento por lo que pueda aportar de manera individualizada para cada caso.

10 OJEA RUA, M: “Trastornos del Espectro Autista” intervención psicoeducativa integrada en el curriculum; Revistas Española de Pedagogía; n 237; Págs. 333 a 350.

${ }^{11}$ LOPEZ GOMEZ, S: GARCIA ALVAREZ, C; ORDOÑEZ BLANCO, S.M: "La intervención escolar en los Trastornos del Espectro Autista”; Revista Gallego Portuguesa de Psicoloxia e Educación; Año 12; Vol. 16; 2008; Págs. 121 a 131.

12 CORREDOIRA LÓPEZ, M: "La inclusión como respuesta educativa al alumnado con TEA"; Maremagnum. n 22; 2018; Págs. 101 a 110.
} 
existe y hay que acudir a criterios propios de otras ciencias, como: empatía, asertividad, equidad... para entender los fenómenos y poder darle una calificación jurídica. Pero desde un tiempo a esta parte se han producidos enormes avances en la diagnosis y clasificación jurídica de la diversidad producida por las incapacidades de origen intelectual y la forma diferente de percibir el mundo en que se desenvuelve y que no afecta a la inteligencia.

Es cierto que en la aplicación existe un margen de individualización, ya sea vía sentencia o vía resolución administrativa. Es conocido que el derecho ha avanzado en el aspecto tuitivo con ciertos grupos sociales como son: menores, mujeres, tercera edad o personas con capacidades diversas. Una situación que se ha dado tanto en las cuestiones que afecta al derecho privado, como a las que afecta al derecho público. Siendo una multitud de normas las que insiste en este aspecto de cuidado y tutela de aquellos que se consideran más débiles, con lo que se conculca en cierto modo la tradicional visión de lo que se considera igualdad, pero se defiende lo que podemos llamar actualmente equidad, que consiste en dar a cada uno lo que necesita de acuerdo a sus características y situaciones personales. Podemos decir que en la actualidad nadie estaría dispuesto a contradecir esta preocupación social que tiende a mejorar las relaciones y a defender a quienes tiene una percepción diferente de la realidad. Que se busca la individualización del beneficiario de la ley y actuar de acuerdo a su entorno y a sus necesidades. Que se han superado los modelos de marginación o rehabilitación, propio de otras épocas, que no incluían a los discapacitados en la sociedad, creando un mundo aparte para ellos.

Aunque, cuando hablamos de discapacidades, se trata de derechos individuales, o mejor dicho de la individualización de los derechos a la persona concreta; son las propias leyes estatales de derecho público las que han generado estrategias para dotar a las personas que está afectadas de estos problemas de los recursos necesarios para que esa pretendida igualdad se haga efectiva.

Se ha declarado una serie de derechos individuales, que tienen su razón de ser en los propios preceptos constitucionales, que amparan a todas las personas y que se convierten en más complejos cuando se trata de garantizarlos a las personas que tienen cualquier tipo de discapacidad, tanto a la hora de ejercer sus derecho personales, como en función de las ayudas que podrían recibir por su situación concreta ${ }^{13}$, donde se incluyen derechos de carácter privado y público, incluyendo en más necesario en la actualidad: a todo tipo de información ${ }^{14}$, u otros más específicos como los de consumidores $^{15}$. Si bien aún quedan muchas cuestiones pendientes de resolver en todos los campos del derecho ${ }^{16}$

\footnotetext{
13 CERMI: Guía de fácil uso de la Convención Internacional sobre los derechos de las personas con discapacidad para operadores jurídicos 2019; La guía se puede conseguir en internet mediante el siguiente

acceso:https://www.cermi.es/sites/default/files/docs/colecciones/Gu\%C3\%ADa\%20de\%20f\%C3\%A1cil \%20uso.pdf La guía pretende ser un indicador, no solo de estos derechos, también de las posibilidades concretas de actuación para tener acceso a estos derechos.

14 SERRANO MASCARAQUE, E: "Marco jurídico referido a la discapacidad: especial referencia a la eaccesibilidad”; Cuadernos de Educación Multimedia; Vol. 20; 2009; Págs. 75 a 111.

${ }^{15}$ Derechos de los consumidores y usuarios con discapacidad; CERMI; 2012.

16 ALCAIN MARTINES, E: La convención Internacional sobre los derechos de las personas con discapacidad; Tirant lo Blanch; 2015; Obra colectiva dedicada a destacar todo el tipo de cuestiones pendientes sobre discapacidad en España.
} 


\subsection{El recorrido en busca de la inclusión.}

La Convención Internacional sobre los Derechos Humanos de las Personas con discapacidad, adoptada por las Naciones Unidas en el 2006, y ratificada por España en el 2008; aporta una legislación general sobre la que se ha ido construyendo toda una estructura de normalización, protección, generalización y estructuración de la nueva idea de discapacidad, que ha de convivir y ser desarrollada con la clásica idea de incapacidad. Este planteamiento se basa en dos propuestas generales:

- Art. 1: son personas con discapacidad aquellas que tengan deficiencias físicas, mentales, intelectuales o sensoriales a largo plazo que puedan impedir su participación plena y efectiva en la sociedad, en igualdad de condiciones con los demás.

- Art. 4: los Estados Partes se comprometen a asegurar y promover el pleno ejercicio de todos los derechos humanos y libertades fundamentales de las personas con discapacidad sin discriminación alguna por motivos de discapacidad. A tal fin, los Estados Partes se comprometen a adoptar todas las medidas legislativas, administrativas y de otra índole que sean pertinentes para hacer efectivos los derechos reconocidos en la presente Convención.

Se han establecido para el desarrollo de estas propuestas dos recorridos diferentes: la discapacidad, de carácter público y amparada por la legislación de carácter administrativo y sanitario, de otro lado la incapacidad de carácter privado, con el sistema de declaración que aporta el derecho civil, reservado al ámbito más íntimo de quien la parece. Es necesario diferenciar la tutela que se ofrecen en cada caso.

\subsection{La protección jurídica de las personas con discapacidad.}

El RDL 1/2013 que desarrolla la Ley de Derechos de las Personas con Discapacidad y su inclusión social. La discapacidad desde el punto de vista administrativo viene regulada por la legislación de Seguridad Social ${ }^{17}$, que no acredita la incapacidad de obrar de una persona. En cuanto a la acreditación de la discapacidad, en necesario contar con el certificado expedido por el INSERSO (instituto de migraciones y servicios sociales) o el órgano competente de las Comunidades Autónomas. El procedimiento viene regulado por el RD 1971/1999 de 23 de diciembre $^{18}$; modificado por el RD 1856/2009 de 4 de diciembre ${ }^{19}$. En esta norma vienen unos anexos con los baremos en donde se recogen los porcentajes de valoración

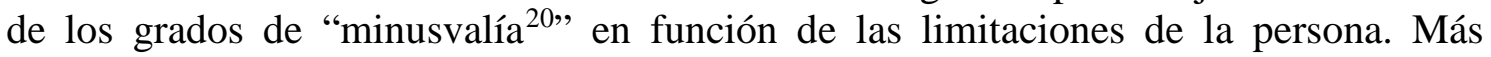
complicada es la valoración de la "enfermedad mental" como se puede apreciar por la lectura del propio baremo, su definición es mucho más abstracta que las correspondientes a las discapacidades físicas.

\footnotetext{
${ }^{17}$ artículo 367 RDleg 8/2015, de 30 octubre, TRLGSS, o norma que lo sustituya.

${ }^{18}$ La transferencia a las Comunidades Autónomas de las competencias en esta materia, obligó a dictar este decreto que unifica los criterios en la concesión del grado de minusvalía.

${ }^{19}$ Esta modificación lo que hace es cambiar todas las referencias a minusvalía por discapacidad.

${ }^{20}$ Aunque la palabra como tal ha quedado excluida de nuestros textos legales de forma genérica, en algunos casos en concreto todavía es posible encontrarla en algunos casos, como ocurre con las deducciones familiares del IRPF.
} 
El tratamiento jurídico de las personas necesitadas de protección ha existido en derecho privado desde tiempo inmemorial; la admisión de una responsabilidad social por parte de la administración es mucho más reciente, complicándose al ampliarse a cada vez más grupos sociales desfavorecidos que pueden acceder a este tipo de ayuda a los que encuadrar dentro de una legislación adecuada resulta cada vez más complejo por no tratarse de situaciones homogéneas que puedan encuadrarse en una definición jurídica. Son necesarios criterios de carácter técnico que requiere que el derecho se apoye en ciencias médicas, psicológicas y de otras ramas de la sanidad para poder concretar como baremar y proteger estas realidades individuales. Una realidad que, debe proteger tanto los casos congénitos, como aquellos que son sobrevenidos y que están equiparados ${ }^{21}$.

\subsection{Proceso de modificación de la capacidad}

La Ley 1/2000 (modificada por Ley 15/2015 de modificación de la Jurisdicción Voluntaria y Ley 8/2015 de protección a la infancia) que han convertido este derecho en prioritario ${ }^{22}$. En esta ley se mejora el principio fundamental en esta materia: la modificación de la capacidad de las personas desarrollada por la Convención del Derecho de las Personas con discapacidad a la que ya nos hemos referido. El término capacidad de obrar, que está limitado, frente al de capacidad jurídica que es consustancial a toda persona, solo se obtiene por la mayoría de edad y puede ser modificado en determinados casos (art. 200 y 322 CC). Estaríamos hablando de una modificación de la capacidad, bien de carácter temporal o permanente, ya sea de carácter patrimonial, adaptativa o interpersonal. Se caracteriza por una enfermedad o deficiencia física o psíquica que le impida gobernarse por sí misma.

El proceso está regulado por el art 756 y ss. de la LEC 1/2000: quien la puede solicitar, pruebas que ha de aportar, intervención del Ministerio Fiscal ${ }^{23}$... Se permite la entrada de terceros que tengan relación directa con la persona a la que se está inhabilitando, siempre a criterio del juzgador. Es un proceso que permite todos los tipos de prueba y acaba con sentencia firme o una resolución administrativa en la que se determina en la situación en la que queda la persona estudiada, con efecto a partir del momento de dictar la misma. Declarando el régimen de guarda y tutela y siendo graduable y reversible. Debiendo nombrarse a una persona que le acompañe, bien como tutor de los bienes o curador o alguna más compleja como es el caso del fideicomisario en las sucesiones. Una faceta que corresponde al derecho privado y en el que este trabajo no entramos, aunque apuntamos que en el momento actual estas figuras están sometidas a revisión ${ }^{24}$. Consecuencia del procedimiento de modificación de la

\footnotetext{
${ }^{21}$ SAN JULIAN PUIG, V: "Discapacidad intelectual sobrevenida: proliferación de herramientas jurídicas poco utilizadas. Estudio de sus causas"; La convención internacional sobre los derechos de las personas con discapacidad; Tirant lo Blanch; 2015; Págs. 527 a 536.

${ }^{22}$ Con repercusiones jurídicas que llegan a los efectos penales, aunque escapan a este estudio.

${ }^{23}$ VARIOS AUTORES: Manual de buenas prácticas del Ministerio Fiscal en la protección a las personas con discapacidad. Fundación Aequitas. 2010. Al tratarse de un libro de descarga gratuita, se incluye el enlace: http://aequitas.notariado.org/liferay/c/document_library/get_file?uuid=feff30a0-8ee848e9-bd6c-36117a943506\&groupId=10228

${ }^{24}$ CABELLO DE ALBA, F: “Alternativas desde el punto de vista notarial a la incapacitación a la luz de la Convención; La convención internacional de los derechos de las personas con discapacidad; Tirant lo Blanch; 2015; Págs. 81 a 92.
} 
capacidad, es la valoración concreta de la persona en cuestión. En el caso de los TEA,S, con mayor dificultad por los motivos que ya hemos comentado ${ }^{25}$

Cabría plantearse la posibilidad de adopción de un menor que estuviese afectado por trastornos que disminuyan su capacidad y en este caso habría que tener en cuenta también la Ley 8/2015 y la LO 26/2015 ambas de protección a la infancia y a la adolescencia. La Jurisprudencia ha delimitado una nueva posibilidad, como es dotar un patrimonio protegido para personas con discapacidad psíquica superior al 33\% sin necesidad de que las mismas estén incapacitadas ${ }^{26}$. Lo que se adapta perfectamente a la situación de discapacidad del TEA, que puede estar calificado por encima del mínimo sin que obligue a incapacitarlo.

\section{La valoración jurídica de la discapacidad psíquica.}

La primera tarea administrativa frente a la discapacidad es la necesidad de una valoración de la misma. Una valoración que tiene incidencia en cuanto a la graduación de las discapacidades y el encuadramiento administrativo por lo que a ayudas o beneficios de cualquier tipo respecta. Valoración que se realiza de acuerdo a unas tablas; comprensibles cuando se trata de discapacidades de tipo físico. Mucho más complicado en el caso de las que afectan a cuestiones de tipo mental.

De Forma general existen tres estadios: menos del 33\%, que en todo caso sería una discapacidad moderada y no sujeta a ningún tipo de beneficio, o en todo caso, muy escaso. Entre el 33\% y el 66\%, en el que se considera una discapacidad grave, que requiere un tratamiento favorable por parte de la administración. Por último, una discapacidad superior al 66\%, que es la considerada muy grave y a la que se le presta la máxima ayuda, además de gozar de una serie de beneficios extraordinarios. Paradójicamente, cuando se clasifican a los incapaces, las valoraciones se realizan de forma diferente, de manera que los grados que se manejan $\operatorname{son}^{27}$ : Clase 1: nula, desde $0 \%$. Clase 2: Discapacidad leve, $1 \%$ a $24 \%$. Clase 3: Discapacidad moderada, $25 \%$ a 49\%. Clase 4: Discapacidad grave, desde el 50\% a 70\%. Clase 5. Discapacidad muy grave, más del 70\% de discapacidad. Como se aprecia la clase no coincide con los tipos a efectos de beneficio de cualquier tipo. Por lo que lo importante a cualquier efecto, no es la clase, sino que se trata de saber el porcentaje de la misma.

Esta enorme variedad de casuística es la que ha dado lugar a la denominación que se ha dado a este síndrome que abarca un auténtico "espectro" de casos, que complica gravemente su clasificación y aún más su calificación. Se puede apreciar que las horquillas de discapacidad que se tratan, no se corresponden con los tipos de acuerdo a la clasificación que hemos visto, lo que ya de por sí dificulta este tipo de baremación.

La idea de este trabajo es entrar en las categorizaciones y valoraciones de las discapacidades de tipo intelectual, por lo que parece imprescindible incluir la misma, a excepción de las situaciones sin discapacidad, a efectos de poder buscar la clasificación en la que piensa que debería estar cada persona a quien valorar:

1) Valoración de la Discapacidad atendiendo a criterios generales de funcionalidad:

\footnotetext{
${ }^{25}$ FUENTES BIGGI, J Y OTROS: “Guía de las buenas prácticas para el tratamiento de los trastornos del espectro autista”; Revista Neurológica; n 43; 2006; Págs. 425-438

${ }^{26}$ sentencia del TS, Sala Primera, de lo Civil, de fecha 29 de abril de 2009

${ }^{27}$ RDL 1971/1999 de 23 de diciembre.
} 
Clase II: Discapacidad leve (1-24\%):

a) La capacidad para llevar a cabo una vida autónoma está conservada o levemente disminuida, de acuerdo a lo esperable para un individuo de su edad y condición, excepto en períodos recortados de crisis o descompensación.

b) Pueden mantener una actividad laboral normalizada y productiva excepto en los períodos de importante aumento del estrés psicosocial o descompensación, durante los que puede ser necesario un tiempo de reposo laboral junto a una intervención terapéutica adecuada.

c) Cumplen los criterios para el diagnóstico de trastorno orgánico de la personalidad; síndrome post-conmocional u otros trastornos mentales orgánicos.

Clase III: Discapacidad moderada (25-59\%):

a) Restricción moderada en las actividades de la vida cotidiana (incluyendo los contactos sociales) y en la capacidad para desempeñar un trabajo remunerado en el mercado laboral. La medicación y/o el tratamiento «son necesarios de forma habitual». Si, a pesar de ello, persiste la sintomatología clínicamente evidente: Que «interfiere notablemente en las actividades de la persona»: Se asignará un porcentaje de discapacidad comprendido entre el 45 y 59\%. Que «no interfiere notablemente en las actividades de la persona»: Se asignará un porcentaje de discapacidad comprendido entre el 25 y 44\%.

b) Las dificultades y síntomas pueden agudizarse en períodos de crisis o descompensación. Fuera de los períodos de crisis: El individuo es capaz de desarrollar una actividad laboral normalizada y productiva la mayor parte del tiempo, con supervisión y ayuda: Se asignará un porcentaje de discapacidad comprendido entre el 25 y $45 \%$.

El individuo sólo puede trabajar en ambientes laborales protegidos con supervisión mínima: Se asignará un porcentaje de discapacidad comprendido entre el 45 y 59\%.

c) Presencia de alguna de las características clínicas siguientes: Trastornos volitivos: Inconstancia, abulia, cambios de humor.

Clase IV: Discapacidad grave (60-74 por 100):

a) Restricción marcada de las actividades de la vida cotidiana. Precisa supervisión intermitente en ambientes protegidos y total fuera de ellos.

b) Marcada disminución de su capacidad laboral, puesta de manifiesto por deficiencias importantes en la capacidad para mantener la concentración, continuidad y ritmo en la ejecución de las tareas y repetidos episodios de deterioro o descompensación asociados a las actividades laborales, como consecuencia del proceso en adaptarse a circunstancias estresantes. No puede mantener una actividad laboral normalizada y con dificultad en centros de Educación Especial. Puede acceder a centros y/o actividades ocupacionales, aunque, incluso con supervisión, el rendimiento suele ser pobre o irregular.

c) Presencia de alguno de los siguientes síntomas: Irritabilidad, ira inmotivada... Impulsividad con fallo en el autocontrol. Suspicacia y paranoidismo.

Clase V: Discapacidad muy grave (75 por 100):

a) Repercusión extrema de la enfermedad o trastorno sobre el individuo, manifestado por incapacidad para cuidar de sí mismo ni siquiera en las actividades básicas de la vida cotidiana. Por ello, necesitan de otra u otras personas de forma constante.

b) No existen posibilidades de realizar trabajo alguno, ni aun en centros ocupacionales supervisados.

c) Presencia de alguno de los siguientes síntomas: Alteración de la esfera instintivo-afectiva. Perseveración ideativa. Deterioro cognitivo.

\section{2) Esquizofrenia y trastornos paranoides:}

Clase II: Discapacidad leve (1-24\%). 
a) La capacidad para llevar a cabo una vida autónoma está conservada o levemente disminuida, de acuerdo a lo esperable para un individuo de su edad y condición, excepto en períodos recortados de crisis o descompensación.

b) Pueden mantener una actividad laboral normalizada y productiva excepto en los períodos de importante aumento del estrés psicosocial o descompensación, durante los que puede ser necesario un tiempo de reposo laboral junto a una intervención terapéutica adecuada.

c) Cumplen los criterios para el diagnóstico de esquizofrenia de cualquier tipo o trastorno paranoide.

Clase III: Discapacidad moderada (25-59\%):

a) Restricción moderada en las actividades de la vida cotidiana (la cual incluye los contactos sociales) y en la capacidad para desempeñar un trabajo remunerado en el mercado laboral. La medicación y/o el tratamiento psico-terapéutico «pueden ser necesarios de forma habitual». Si, a pesar de ello, persiste la sintomatología clínicamente evidente: Que interfiere notablemente en las actividades de la persona: Se asignará un porcentaje de discapacidad comprendido entre el 45 y 59\%. Que no interfiere notablemente en las actividades de la persona: Se asignará un porcentaje de discapacidad comprendido entre el 25 y 44\%.

b) Las dificultades o síntomas pueden agudizarse en períodos de crisis o descompensación. Fuera de los períodos de crisis: El individuo es capaz de desarrollar una actividad laboral normalizada y productiva la mayor parte del tiempo, con supervisión y ayuda: Se asignará un porcentaje de discapacidad comprendido entre el 25 y 45\%. El individuo sólo puede trabajar en ambientes laborales protegidos con supervisión mínima: Se asignará un porcentaje de discapacidad comprendido entre el 45 y $59 \%$.

c) Presencia de alguna de las características clínicas siguientes: Persistencia de síntomas psicóticos por más de un año. Dificultad marcada en la relación interpersonal o actitudes autistas.

Clase IV: Discapacidad grave (60-74\%):

a) Marcada restricción de las actividades de la vida cotidiana (posibilidades de desplazarse, de preparar e ingerir los alimentos, de atender a su higiene personal y al vestido, de cuidar de su hábitat y realizar las tareas domésticas, de comunicarse y tener contactos sociales), lo que obliga a supervisión intermitente en ambientes protegidos y total fuera de ellos.

b) Marcada disminución de su capacidad laboral, puesta de manifiesto por deficiencias importantes en la capacidad para mantener la concentración, continuidad y ritmo en la ejecución de las tareas y repetidos episodios de deterioro o descompensación asociados a las actividades laborales, como consecuencia del fracaso en adaptarse a circunstancias estresantes. No puede desempeñar una actividad laboral con regularidad. Puede acceder a centros ocupacionales protegidos, aunque incluso con supervisión el rendimiento suele ser pobre o irregular.

c) Presencia de alguna de las características clínicas siguientes: Mala respuesta a los tratamientos con persistencia de sintomatología. Necesidad permanente de tratamiento con internamientos reiterados. Asociaciones laxas de ideas, tendencia a la abstracción, apragmatismo. Síntomas alucinatorios y delirantes crónicos.

Clase V: Discapacidad muy grave (75 \%):

a) Repercusión extrema de la enfermedad o trastorno sobre el individuo, manifestado por incapacidad para cuidar de sí mismo, ni siquiera en las actividades básicas de la vida cotidiana. Por ello, necesitan de otra u otras personas de forma constante.

b) No existen posibilidades de realizar trabajo alguno, ni aun en centros ocupacionales supervisados.

c) Presencia de alguna de las siguientes características clínicas: Trastornos severos en el curso y/o contenido del pensamiento que afectan al sujeto la mayor parte del tiempo. Pérdida del 
contacto con la realidad. Trastornos disperceptivos permanentes. Institucionalización prolongada. Conductas disruptivas reiteradas.

\section{3) Trastornos afectivos:}

Clase II: Discapacidad leve (1-24\%):

a) La capacidad para llevar a cabo una vida autónoma está conservada o levemente disminuida, de acuerdo a lo esperable para un individuo de su edad y condición, excepto en períodos recortados de crisis o descompensación.

b) Pueden mantener una actividad laboral normalizada y productiva excepto en los períodos de importante aumento del estrés psicosocial o descompensación, durante los que puede ser necesario un tiempo de reposo laboral junto a una intervención terapéutica adecuada.

c) Cumplen los criterios de diagnóstico para cualquier tipo de trastorno afectivo.

Clase III: Discapacidad moderada (25-59\%):

a) Restricción moderada en las actividades de la vida cotidiana (la cual incluye los contactos sociales) y en la capacidad para desempeñar un trabajo remunerado en el mercado laboral. La medicación y/o el tratamiento psico-terapéutico pueden ser necesarios de forma habitual. Si, a pesar de ello, persiste la sintomatología clínicamente evidente: Que «interfiere notablemente en las actividades de la persona»: Se asignará un porcentaje de discapacidad comprendido entre el 45 y 59 \%. Que no interfiere notablemente en las actividades de la persona: Se asignará un porcentaje de discapacidad comprendido entre el 25 y 44\%

b) Las dificultades y síntomas pueden agudizarse en períodos de crisis o descompensación. Fuera de los períodos de crisis: El individuo es capaz de desarrollar una actividad normalizada y productiva la mayor parte del tiempo, con supervisión y ayuda: Se asignará un porcentaje de discapacidad comprendido entre el 25 y 45\%. El individuo sólo puede trabajar en ambientes laborales protegidos, con supervisión mínima: Se asignará un porcentaje de discapacidad comprendido entre el 45 y 59\%.

c) Presencia de alguna de las siguientes características clínicas: Episodios maníacos recurrentes. Depresión mayor de evolución crónica (más de dieciocho meses sin remisión). Mala respuesta a los tratamientos. Trastorno bipolar con recaídas frecuentes que requieran tratamiento. Como posible orientación: más de dos al año; más de cinco en los últimos tres años; más de ocho en los últimos cinco años... Depresión recurrente (incluso breve) con tentativas de suicidio. Presencia de síntomas psicóticos.

Clase IV: Discapacidad grave (60-74\%):

a) Grave restricción de las actividades de la vida cotidiana (posibilidades de desplazarse, de preparar e ingerir los alimentos, de atender a su higiene personal y al vestido, de cuidad de su hábitat y realizar las tareas domésticas, de comunicarse y tener contactos sociales), lo que obliga a supervisión intermitente en ambientes protegidos y total fuera de ellos.

b) Grave disminución de su capacidad laboral, puesta de manifiesto por deficiencias importantes en la capacidad para mantener la concentración, continuidad y ritmo en la ejecución de las tareas y repetidos episodios de deterioro o descompensación asociados a las actividades laborales, como consecuencia del fracaso en adaptarse a circunstancias estresantes. No puede desempeñar una actividad normalizada con regularidad. Puede acceder a centros y/o actividades ocupacionales protegidos, aunque incluso con supervisión el rendimiento suele ser pobre o irregular.

c) Presencia de alguna de las siguientes características clínicas: Depresión mayor encronizada (más de tres años sin remisión apreciable). Trastorno bipolar resistente al tratamiento. Sintomatología psicótica crónica.

Clase V: Discapacidad muy grave (75\%): 
a) Repercusión extrema de la enfermedad o trastorno sobre el individuo, manifestado por incapacidad para cuidar de sí mismo ni siquiera en las actividades básicas de la vida cotidiana. Por ello, necesitan de otra u otras personas de forma constante.

b) No existen posibilidades de realizar trabajo alguno, ni aun en centros ocupacionales supervisados.

c) Presencia de alguna de las características clínicas siguientes: Síntomas de depresión y/o manía (o hipomanía) constantes. Hospitalizaciones reiteradas por el trastorno. Ausencia de recuperación en los períodos intercríticos.

\section{4) Trastornos de ansiedad, adaptativos y somatomorfos:}

Clase II: Discapacidad leve (1-24 por 100):

a) La capacidad para llevar a cabo una vida autónoma está conservada o levemente disminuida, de acuerdo a lo esperable para un individuo de su edad y condición, excepto en períodos recortados de crisis o descompensación.

b) Pueden mantener una actividad laboral normalizada y productiva excepto en los períodos de importante aumento del estrés psicosocial o descompensación, durante los que puede ser necesario un tiempo de reposo laboral junto a una intervención terapéutica adecuada.

c) Presencia de criterios de diagnóstico suficientes para cualquiera de los tipos de trastornos de ansiedad, adaptativos o somatomorfos.

Clase III: Discapacidad moderada (25-59\%):

a) Restricción moderada en las actividades de la vida cotidiana (la cual incluye los contactos sociales) y en la capacidad para desempeñar un trabajo remunerado en el mercado laboral. La medicación y/o tratamiento psicoterapéutico pueden ser necesarios de forma continuada, a pesar de lo cual puede persistir sintomatología clínicamente evidente: Que «interfiere notablemente en las actividades de la persona»: Se asignará un porcentaje de discapacidad comprendido entre el 45 y 59\%. Que «no interfiere notablemente en las actividades del paciente»: Se asignará un porcentaje de discapacidad entre el 25 y 44\%.

b) Las dificultades y síntomas pueden agudizarse en períodos de crisis o descompensación. Fuera de los períodos de crisis: El individuo es capaz de desarrollar una actividad laboral normalizada y productiva la mayor parte del tiempo, con supervisión y ayuda: Se asignará un porcentaje de discapacidad comprendido entre el 25 y 44\%. El individuo sólo puede trabajar en ambientes laborales protegidos con supervisión mínima: Se asignará un porcentaje de discapacidad comprendido entre el 45 y 59\%.

c) Presencia de alguna de las siguientes características clínicas: Cuadros que presentan crisis que requieran ingreso para su hospitalización. Grave alteración en la capacidad de relación interpersonal y comunicación.

Clase IV: Discapacidad grave (60-74 por 100):

a) Grave restricción de las actividades de la vida cotidiana (posibilidades de desplazarse, de preparar e ingerir los alimentos, de atender a su higiene personal y al vestido, de cuidar de su hábitat y realizar las tareas domésticas, de comunicarse y tener contactos sociales), lo que obliga a supervisión intermitente en ambientes protegidos y total fuera de ellos.

b) Grave disminución de su capacidad laboral, puesta de manifiesto por deficiencias importantes en la capacidad para mantener la concentración, continuidad y ritmo en la ejecución de las tareas y repetidos episodios de deterioro o descompensación asociados a las actividades laborales, como consecuencia del fracaso en adaptarse a circunstancias estresantes. No puede desempeñar una actividad laboral con regularidad. Puede acceder a centros ocupacionales protegidos, aunque, incluso con supervisión, el rendimiento suele ser pobre o irregular.

c) Presencia de alguna de las siguientes características clínicas: Cuadros con grave repercusión sobre la conducta y mala respuesta al tratamiento:

Clase V: Discapacidad muy grave (75 por 100). 
a) Repercusión extrema de la enfermedad o trastorno sobre el individuo, manifestado por incapacidad para cuidar de sí mismo ni siquiera en las actividades básicas de la vida cotidiana. Por ello, necesitan de otra u otras personas de forma constante.

b) No existen posibilidades de realizar trabajo alguno, ni aun en centros ocupacionales supervisados.

c) Trastorno grave resistente por completo a todo tratamiento.

\section{5) Trastornos de la personalidad:}

Clase II: Discapacidad leve (1-24 por 100):

a) La capacidad para llevar a cabo una vida autónoma está conservada o levemente disminuida, de acuerdo a lo esperable para un individuo de su edad y condición, excepto en períodos recortados de crisis o descompensación.

b) Pueden mantener una actividad laboral normalizada y productiva excepto en los períodos de importante aumento del estrés psicosocial o descompensación, durante los que puede ser necesario un tiempo de reposo laboral junto a una intervención terapéutica adecuada.

c) Presencia de criterios de diagnóstico para cualquiera de los tipos de trastorno de la personalidad.

Clase III: Discapacidad moderada (25-59\%).

a) Restricción moderada de las actividades de la vida cotidiana (la cual incluye los contactos sociales) y en la capacidad para desempeñar un trabajo remunerado en el mercado laboral. La medicación y/o tratamiento psicoterapéutico pueden ser necesarios de forma habitual, a pesar de lo cual puede persistir sintomatología clínicamente evidente: que interfiere notablemente en las actividades de la persona: se asignará un porcentaje de discapacidad comprendido entre el 45 y 59 \%. que no interfiere notablemente en las actividades del paciente: se asignará un porcentaje de discapacidad comprendido entre el 25 y $44 \%$.

b) Las dificultades y síntomas pueden agudizarse en períodos de crisis o descompensación. Fuera de los períodos de crisis: el individuo es capaz de desarrollar una actividad laboral normalizada y productiva la mayor parte del tiempo, con supervisión y ayuda: se asignará un porcentaje de discapacidad comprendido entre el 25 y 44\%.

c) Presencia de alguna de las siguientes características clínicas: Cumplir criterios para el diagnóstico.

Clase IV: Discapacidad grave (60-74\%).

a) Grave restricción de las actividades de la vida cotidiana (posibilidades de desplazarse, de preparar e ingerir los alimentos, de atender a su higiene personal y al vestido, de cuidad de su hábitat y realizar las tareas domésticas, de comunicarse y tener contactos sociales), lo que obliga a supervisión intermitente en ambientes protegidos y total fuera de ellos.

b) Grave disminución de su capacidad laboral, puesta de manifiesto por deficiencias importantes en la capacidad para mantener la concentración, continuidad y ritmo en la ejecución de las tareas y repetidos episodios de deterioro o descompensación asociados a las actividades laborales, como consecuencia del fracaso en adaptarse a circunstancias estresantes. No puede desempeñar una actividad laboral con regularidad. Puede acceder a centros ocupacionales protegidos, aunque, incluso con supervisión, el rendimiento suele ser pobre o irregular.

c) Trastornos de personalidad cuyas características clínicas reúnan alguno de los requisitos siguientes: Necesidad de internamiento.

La lectura de dicha relación nos lleva a concluir que los términos en muchos casos no son fáciles de comprender y por lo tanto la valoración depende totalmente del equipo técnico que hace la misma. Difíciles de entender desde el punto de vista jurídico y más aún para los padres que ven con perplejidad la complicación para clasificar la situación concreta de su hijo. 
Estas tablas determinan el grado de discapacidad que es el que otorga las ayudas que este artículo viene a exponer. De manera que el primer proceso debe pasar por valorar al discapacitado para ver en qué grado se clasificaría su situación presente. Pues no olvidemos que en el caso de los TEA,S las situaciones son reversibles y las valoraciones pueden variar en cada revisión que se haga de la persona que lo manifiesta.

\section{AYUDAS SOCIALES A LAS DISFUNCIONALIDADES PSIQUICAS.}

\subsection{La protección de la discapacidad en general.}

El interés por la discapacidad aparece en la propia Constitución, regulado en los artículos: 1.1 en cuanto al valor de la igualdad; 9.2 en cuanto conmina a los poderes públicos a remover los obstáculos que impidan la igualdad efectiva; 14 en cuanto a la no discriminación; 49 en cuanto a las políticas de inclusión de los discapacitados; como complemento de todo ello para promover esa igualdad, existen herramientas en la política social y fiscal ${ }^{28}$ para tal fin, que se ha venido desarrollando en los últimos años y que queremos exponer en este apartado. Igualmente, el art. 2.1 LGT dispone que los tributos pueden servir como instrumento para atender a la realización de los principios y fines contenidos en la Constitución.

En la banda de planteamientos tuitivos sobre discapacidad aparecen multitud de opciones que benefician a quien está en el espectro de estas situaciones. En concreto, nuestro sistema socio-tributario ha ido creando nuevas figuras para proteger a los discapacitados; tanto en las sucesivas organizaciones de asuntos sociales, como en todo tipo de impuestos. Aparecieron beneficios laborales, tendentes a facilitar la contratación de quien manifiesta este tipo de discapacidades o para animarlos a generar su propio empleo; por último y a ello se han unido algunas empresas que también conceden cierto tipo de ayudas. Medidas que paulatinamente se han ido ampliando desde el conocimiento de la forma en que se manifiesta la discapacidad y que pretenden mejorar la vida de las personas que manifiestan el TEA, bien por aportando o ayudando social y económicamente desde la imposición en el entorno de las personas concernidas ${ }^{29}$.

En cuanto a los grados de discapacidad necesarios para tener acceso a beneficios fiscales debe ser superior al 33\% en cualquier caso, empezando en el mismo las ayudas para las discapacidades psíquicas. Una ventaja frentes a las de tipo físico, que en ocasiones requiere al menos el 65\% para ser beneficiario de algunas de ellas. También en este caso la graduación es importante y podemos decir que se le ha otorgado una mayor protección a la discapacidad de carácter psíquico ${ }^{30}$.

\footnotetext{
${ }^{28}$ JIMENEZ NAVAS, M. ${ }^{\text {a }}$ M: "El mantenimiento de los beneficios fiscales que favorecen la movilidad de las personas con discapacidad en la imposición indirecta”; Quincena Fiscal; nº 21; 2012; Págs. 1 y 2.

${ }^{29}$ ANGOITIA GRIJALBA, M: "Estimación de la renta de las personas con discapacidad a partir de la muestra de declarantes de IRPF”; Es una parte del Trabajo de Carpio, Angoitia y Méndez. XIV Encuentro de Economía Pública; 2007; Es un estudio detallado de los niveles de renta de los discapacitados comparados con quienes no padecen este tipo de deficiencias. Aunque en el mismo no se incluye la situación concreta de los discapacitados psíquicos, es significativo para aportar datos promedios y saber las limitaciones existentes, también en esta materia.

30 DE PABLO VARONA, C: "Reflexiones sobre la protección patrimonial de las personas con discapacidad intelectual. Especial referencia a su fiscalidad (parte 1)”; Revista Síndrome de Down; Volumen 34; noviembre 2017; Pág. 124.
} 


\subsection{Descripción de las ayudas sociales a la discapacidad.}

De una forma genérica existen ayudas, que si bien no son de tipo fiscal realmente inciden sobre la capacidad económica del minusválido en la medida en que reducen su gasto cotidiano al realizar determinadas actividades y que tienen una legislación variopinta, pero que es necesario conocer para explorar sobre las mismas en casos de interés. A continuación, se describen algunas y se remite a lugares de referencia donde se pueden encontrar mayor profundidad en el análisis de las mismas:

- Descuento en actividades deportivas, lúdicas o de ocio ${ }^{31}$.

- Subsidio a la movilidad y compensación de gasto de transporte ${ }^{32}$

- Descuentos para estancias en hoteles ${ }^{33}$.

- Acceso preferente a viviendas de protección oficial ${ }^{34}$.

- Ayudas para la eliminación de barreras ${ }^{35}$.

- Jubilación anticipada a personas con discapacidad superior al $65 \%{ }^{36}$.

- Incremento de la pensión para las personas que superen el $75 \%$ de discapacidad $^{37}$.

- Abono social de electricidad y telefonía para discapacitados superior al $65 \%{ }^{38}$.

- Derecho a rehabilitación a partir del 33\% ${ }^{39}$.

- Mejora en la puntuación para acceso a la escolarización ${ }^{40}$.

- Becas de educación especial ${ }^{41}$.

- Ayudas de transporte escolar ${ }^{42}$.

- Ayudas de comedor escolar ${ }^{43}$.

- Programas de garantía social $^{44}$.

31 Para informarse de este tipo de ayudas, existe una página dedicada a deportes adaptados para personas con discapacidad intelectual: https://fanddi.com.

${ }^{32}$ Para conocer la situación de esta ayuda: https://solidaridadintergeneracional.es/ayuda/5445.

33 http://reservahotel.net/intereses/hoteles-minusv\%C3\%A1lidos/H_1 Para reservas de hotel.

34 Para saber más sobre el acceso a VPO para incapacitados, ver: https://www.discapnet.es/areastematicas/diseno-para-todos/accesibilidad-en-el-hogar/vivienda/donde-vivir/comprar-una-casa

${ }^{35}$ Consultar la página: https://solidaridadintergeneracional.es/ayuda/7255

${ }^{36}$ El mejor sitio para consultar sobre estos beneficios es la página de la Seguridad Social http://www.segsocial.es/wps/portal/wss/internet/Trabajadores/PrestacionesPensionesTrabajadores/10963/28393/1712/41 704

37 https://www.google.com/url?sa=t\&rct=j\&q=\&esrc=s\&source=web\&cd=15\&ved=2ahUKEwj3hfnu5DpAhUDJhoKHQDrCgQQFjAOegQICBAB\&url=https\%3A\%2F\%2Fwww.imserso.es\%2FInterPresent 2\%2Fgroups\%2Fimserso\%2Fdocuments\%2Fbinario\%2Ffpnc.pdf\&usg=AOvVaw3ZR2CQdN-SFDCFzgtyiov Enlace que permite tener acceso a la página del INSERSO y a un PDF con la normativa al respecto.

${ }^{38}$ https://www.tododisca.com/bono-social-electricidad-discapacidad/

39 https://fedace.org/tramites aguda.html

40 https://www.google.com/url?sa=t\&rct=j\&q=\&esrc=s\&source=web\&cd=7\&ved=2ahUKEwj6u7XMgZ HpAhUnDWMBHX1UAFQQFjAGegQIBhAB\&url=https\%3A\%2F\%2Fwww.observatoriodeladiscapaci dad.info\%2Fwp-content\%2Fuploads\%2F2019\%2F04\%2FOED-ALUMNADO-CON-DISCAPACIDADFASE-I.pdf\&usg=AOvVaw3Xda5w_GV0CypxTkX5Sh5F

41 Se pueden consultar en página http://www.educacionyfp.gob.es/contenidos/estudiantes/educacioninfantil/becas-ayudas-premios/necesidad-especifica-apoyo-educativo.html aunque tienen unos plazos concretos de entrega, lo que obliga a tenerlas en cuenta y solicitarlas cuando proceda.

42 https://www.juntadeandalucia.es/servicios/procedimientos/detalle/4997/como-solicitar.html esta es la correspondiente a Andalucía, pero existen para todas las comunidades autónomas.

43 Solicitud en junio en la página http://www.educacionyfp.gob.es/contenidos/estudiantes/educacioninfantil/becas-ayudas-premios/necesidad-especifica-apoyo-educativo.html 
- Programas de formación para la transición a la vida adulta ${ }^{45}$.

- Reducción de impuestos en determinados bienes o servicios (higiene, farmacia, aseo, adquisición y adaptación de vehículos.... $)^{46}$

- Exención de pago de tasas en la Universidad ${ }^{47}$.

- Reserva de plazas de acceso a la Universidad ${ }^{48}$.

- Programas de apoyo y reserva de habitaciones y pisos tutelados ${ }^{49}$.

- Ayudas a domicilio ${ }^{50}$.

- Atención Personal ${ }^{51}$.

- Servicios de atención diurna ${ }^{52}$.

- Exención de tasas de caza y pesca ${ }^{53}$.

- Tarjeta dorada de RENFE ${ }^{54}$.

- Protección Jurídica ${ }^{55}$.

\section{AYUDAS TRIBUTARIAS A LA DISCAPACIDAD}

\subsection{Ayudas sobre tributos estatales ${ }^{56}$.}

\subsection{1.- Reducción por discapacidad en IRPF.}

\subsubsection{Exenciones.}

La primera situación que hay que comentar en este aspecto es la exención de las prestaciones percibidas por incapacidad absoluta o gran invalidez reconocidas por la

\footnotetext{
${ }^{44}$ https://sid.usal.es/areas/discapacidad/integracion-escolar-educacion-especial/garantia-social.aspx si bien se trata de la página de Castilla León, tiene noticias de todas las comunidades y es una buena guía para quien necesite saber más.

45 https://sede.educacion.gob.es/publiventa/programas-de-formacion-para-la-transicion-a-la-vidaadulta/educacion-especial-y-compensatoria/7750 se trata del acceso a un PDF donde se analiza este tipo de programas y los centros para su implantación.

46 CUATRECASAS, GONZALVES PEREIRA: Guía Práctica de Fiscalidad para Personas con Discapacidad; 2016; APSA; Págs. 59 a 82.

${ }^{47}$ https://www.emagister.com/blog/quien-exenciones-reducciones-la-matricula-universitaria/ se trata de una página genérica. Pero cabria acudir a la página de cada Universidad para ver esta exención.

48 https://sid.usal.es/preguntas-frecuentes/discapacidad/acceso-a-la-universidad.aspx\#a3 aclara esta guía en que consiste el beneficio. Pero se puede acudir a la página de cada Universidad concreta.

${ }^{49}$ https://www.sunrisemedical.es/blog/viviendas-tuteladas

${ }^{50}$ https://www.juntadeandalucia.es/agenciadeserviciossocialesydependencia/es/programas/atendep catalogo /atendep_catalogo_in. Es el portal Andaluz, pero las instrucciones son de tipo general.

${ }^{51}$ https://www.juntadeandalucia.es/agenciadeserviciossocialesydependencia/es/programas/atendep catalogo/atendep_catalogo_info/atendep_catalogo/atendep_catalogo_servicios/atendep_catalogo_servicio s_atenres/wfprogramitem_view_pub

52 COBO MOLINA, C (coordinadora): Protocolo de atención personalizada para personas con discapacidad usuarias de servicios residenciales y de atención diurna; Consejería de Igualdad y Bienestar Social de la Junta de Andalucía; 2016.

${ }^{53}$ No todas las comunidades autónomas tienen esta exención. Es necesario comprobarla.

${ }^{54} \mathrm{https}$ ://www.aesfas.org/que-descuentos-tienen-las-personas-mayores-que-quieran-viajar-en-el-ave. Esta página te muestra los descuentos en el caso de viajes, ya que se puede obtener la tarjeta dorada al tener una minusvalía superior al 33\%.

55 https://www.mscbs.gob.es/ssi/discapacidad/informacion/leyGeneralDiscapacidad.htm página oficial para saber más sobre esto.

${ }^{56}$ CV5403/1999 para tener derecho a cualquier beneficio fiscal hay que acreditar la discapacidad.
} 
seguridad social u organismo que la sustituyan hasta tres veces el importe del IPREM ${ }^{57}$ (Art. 7.f LIRPF), aunque tiene que ser consideradas y reconocidas como tal por los organismos de la Seguridad Social. La consecución y calificación como tales no es tarea fácil, pues necesita cumplir unos requisitos determinados que solo se dan de forma excepcional y que es necesario tener en cuenta a efectos de aplicar la exención ${ }^{58}$. Generalmente Hacienda en la información fiscal que facilita a los contribuyentes, cuando los ingresos gozan de esta exención, no los hace constar, de manera que facilita al contribuyente el conocimiento de que cantidades debe incluir en su declaración como ingresos sujetos.

\subsubsection{Reducciones por circunstancias personales.}

El sistema que utiliza nuestra legislación sobre IRPF es reduciendo la base imponible del impuesto en las cantidades que se indican. La reducción se aplica tanto a las circunstancias personales y familiares, como a otros mínimos que se han ido generando a lo largo del tiempo. La distinción se realiza por el porcentaje de discapacidad, distingüendo entre más de 65\%, más de 33\% y discapacidad declarada judicialmente, con independencia del grado de la misma

Si el discapacitado es el declarante, superior al 33\% la reducción es de 3.500€ $\mathrm{y}$ en caso de que se acredite la necesidad de ayuda de terceras personas o movilidad reducida o sea superior al 65\%, la reducción es de $7.750 €$

En el caso de otras personas incluidas en la declaración, además del contribuyente se aplica, de forma directa, nuestra ley de IRPF reconoce una reducción en la base imponible por discapacidad, sin importar de que tipo. 3.000€ hasta el 33\% y $9.000 €$ a partir del $65 \%{ }^{59}$. Estas cantidades se pueden incrementar en otros $3.000 €$ para el caso de que tenga movilidad reducida o necesite ayuda. Se aplica no solo a los titulares de la declaración, también a los descendientes y ascendientes que convivan con ellos y declaren de forma conjunta. Así mismo la posibilidad de deducción por descendiente se mantiene cuando la patria potestad sea prorrogada ${ }^{60}$.

\subsubsection{Reducciones por rendimiento del trabajo.}

En el caso de que discapacitados en paro acepten un puesto de trabajo que requiera trasladar su residencia habitual se deducirán de dicho rendimiento una cantidad adicional de $3.500 €$ frente a los $2.000 €$ de un trabajador normal. En caso de que necesiten la ayuda de otra persona, esta reducción adicional será de 7.750€ con límite en

\footnotetext{
${ }^{57}$ Indicador Público de Renta de Efectos Múltiples es un índice utilizado por el Estado como referencia en la concesión de ayudas, subvenciones y subsidios. Para 2019 ha quedado fijado en 548,60€ aunque hay que tener en cuenta que son 14 pagas, lo que supone al año 7.680,35 € y la cantidad exenta de renta se eleva a 23-051, $05 €$. Lo que supone una cantidad significativa en cuanto a la posibilidad de ahorro tributario para quienes tienen este beneficio.

${ }^{58}$ RANCAÑO MARTIN, A; ALMAGRO MARTIN, C: "El IRPF y la Convención sobre los Derechos de las Personas con Discapacidad: barreras fiscales que obstaculizan su cumplimiento"; La convención internacional sobre los derechos de las personas con discapacidad; Tirant lo Blanch; 2015; Págs. 527 a 536.

${ }^{59}$ Que se elevan a $3.300 €$ y $9.900 €$ en el caso de Galicia.

${ }^{60}$ ALAMO CERRILLO, R: “Familia e IRPF”; Quincena Fiscal; nº 21; 2016; Pág. 4.
} 
el propio rendimiento (Art. 53.f de la Ley 26/2014). Solo es posible una deducción por declaración.

\subsubsection{Reducciones por actividades económicas.}

En determinados rendimientos de actividades económicas, los contribuyentes con discapacidad podrán hacer una reducción en su renta de $3.264 €$ adicionales a los de cualquier contribuyente (art. 17 Ley 26/2014 de 27 de noviembre).

\subsubsection{Deducciones.}

Aunque no es de fácil aplicación en los casos de las personas que manifiestan el TEA, existe una deducción para la adaptación de la vivienda a los discapacitados. Podría ocurrir que se piense en instalar dispositivos electrónicos complicados que mejoren la vida de estas personas y que puedan acogerse a esta deducción, que debe estar certificada por la Administración. La forma para aplicar la deducción requiere una base máxima ${ }^{61}$.

Una novedad es la deducción de cien euros mensuales por diferentes circunstancias familiares (arts. 58, 59, 81 bis Ley 25/2015 de 28 de julio): hijos con minusvalía; por ser familia numerosa. Incluso un nuevo tipo como es considerar familia numerosa a la formada por dos hijos, cuando uno de ellos tenga una "minusvalía" superior al 33\%, o son ambos padres los que padecen esta discapacidad ${ }^{62}$. La novedad en estas deducciones, es que se pueden cobrar anticipadamente, en lugar de deducirlas en el IRPF, o esperar a la deducción en la declaración. Se abona, aunque no haya obligación de declarar o de pago, pues puede hacerse anticipadamente. Tal vez el mayor problema que presenta estas deducciones es que obliga a quien las percibe a cotizar a la seguridad social, de manera que, en caso de divorcio, si uno de los cónyuges no trabaja, no tendría derecho a la misma ${ }^{63}$.

\subsubsection{Planes de pensiones a favor de personas con discapacidad ${ }^{64}$.}

Las aportaciones se efectúan como en un plan de pensiones, de forma sistemática y con unos máximos fijados en nuestra legislación (Art. 53 LIRPF y 50 y 51 RIRPF). Estas aportaciones son deducibles en IRPF para quienes las aportan. En caso de discapacidad psíquica debe ser igual o superior al 33\%, en caso de incapacidad declarada judicialmente, no es necesario que esté graduada.

Existen unos máximos que en estos casos es de $10.000 €$ siempre que la aportación la haga un familiar.

\footnotetext{
${ }^{61}$ CUBILES SANCHEZ-POBRE, P: "La tributación de la vivienda en el IRPF. Tratamiento fiscal de su adquisición, reforma y arrendamiento ¿Qué se puede mejorar?”; Quincena Fiscal; nº 6; 2012; Págs. 3 a 5.

${ }^{62}$ ROVIRA FERRER, I: "Las nuevas deducciones en el IRPF para las familias numerosas, los familiares a cargo de personas con discapacidad y determinadas familias monoparentales"; Quincena Fiscal; $\mathrm{n}^{\circ}$ 10; 2015; Págs. 4 y ss. CALVO VÉRGEZ, J: "Los nuevos impuestos negativos aplicables en el IRPF”; Revista Aranzadi Doctrinal; nº 5; 2015; Pág. 6.

63 DIAZ CALVARRO, J.M: "Las modificaciones introducidas en las deducciones por maternidad y la deducción por familia numerosa y personas con discapacidad a cargo. ¿Una oportunidad perdida?”; Quincena Fiscal; n ${ }^{\circ}$ 8; 2019; Págs. 7 y 8

${ }^{64}$ DE PABLO VARONA, C: op. Cit; Pág. 119 a 123.
} 
En caso de que la aportación la haga la propia persona con discapacidad el máximo anual será de 24.250€, que actual como máximo cuando son varias las personas que aportan bienes al plan de pensiones (los ascendientes y el propio discapacitado)

Es necesario estudiar la situación de los ingresos de cada cónyuge para ver que aportación es más interesante ${ }^{65}$ pues va a depender de los ingresos de la familia.

El plan de pensiones se puede rescatar a partir de los 45 años del discapacitado y están exentos en la cantidad de tres veces el IPREM (indicador público de renta de efectos múltiples) tributando por encima de esta cantidad tributa como rentas del trabajo. Lo que supone un gran ahorro fiscal en caso de que no tenga otro tipo de ingresos.

Si percibiese otras cantidades provenientes de otro tipo de plan de pensiones no constituido a su favor, tendrá que tributar por ellas como rendimiento ordinario del trabajo que se sumarán a cualquier otra renta procedente de prestaciones de orfandad o viudedad.

\subsubsection{El Patrimonio Protegido ${ }^{66}$.}

La finalidad de un patrimonio protegido es permitir la designación de unos bienes y derechos determinados para que, con ellos, y sus beneficios se haga frente a las necesidades vitales ordinarias y extraordinarias de la persona con discapacidad, aplicables en este caso a las personas que manifiestan TEA,S. Estos bienes y derechos pueden ser de cualquier tipo. Hablamos de dinero, títulos, acciones, emisiones de deuda pública, obligaciones, seguros, rentas vitalicias o temporales, joyas, obras de arte, bienes inmuebles, usufructos, y de cualquier otro derecho con contenido patrimonial. El origen de esta masa lo encontramos en las aportaciones que voluntariamente deseen realizar los familiares más directos de la persona discapacitada ${ }^{67}$. Con ello se constituye un patrimonio directamente vinculado a la persona designada de manera que con los bienes que lo componen y la administración de los mismos, de manera inmediata se pueda hacer frente a las necesidades vitales ordinarias y extraordinarias de las personas con discapacidad sin necesidad de acudir a la institución hereditaria o a la donación.

Formalmente el patrimonio protegido ha de constituirse en escritura pública o por resolución judicial y ha de indicar los bienes, la determinación de las reglas de administración y fiscalización ${ }^{68}$. Los aportantes a un patrimonio protegido se obligan a presentar todos los años el modelo 182, en el que se indican las cantidades entregadas a este tipo de patrimonios, por cada perceptor ${ }^{69}$.

La ley 41/2003 de Protección Patrimonial de las Personas con Discapacidad, en puridad es una ley civil para generar este tipo de patrimonios, pero con repercusiones tributarias $^{70}$ que son las que aquí nos interesa, por el carácter tuitivo que la misma desarrolla. Se trata de un paso más para la ayuda a la discapacidad, pues en definitiva es

\footnotetext{
${ }^{65}$ CPR 2016/62

66 LUCAS DURÁN, M; MARTIN DÉGANO, I: Los patrimonios protegidos de personas con discapacidad; Documentos del IEF; n 4/2014.

67 GUERRA REGUERA, M: "Los patrimonios protegidos. Un instrumento al servicio de las personas discapacitadas y sus familiares”; Quincena Fiscal; nº 14; 2015; Pág. 3

${ }^{68}$ DE HARO IZQUIERDO, M: "Patrimonios protegidos y Trust. Un largo recorrido hacia la asimilación del Trust en nuestro ordenamiento jurídico”: Quincena Fiscal; nº 4; 2016; Pág. 2

${ }^{69}$ GUERRA REGUERA, M: “Los patrimonios protegidos; op cit; Págs. 16 y 17.

${ }^{70}$ Modifica los arts. 54 LIRPF y 71 RIRPF.
} 
un patrimonio dotado de una finalidad, dándole un carácter de especial protección y con una finalidad concreta de satisfacer las necesidades vitales de estas personas; sostenible en su manejo de forma que pueda durar el plazo más largo posible; separado, de manera que quede claramente diferenciado este patrimonio del resto de los bienes de quien lo da o lo recibe. Y protegido, que es la última de las características ${ }^{71}$.

Uno de los aspectos más destacables de la legislación mencionada es la sustitución fideicomisaria, que se produce cuando el testador tiene un heredero judicialmente incapacitado, pudiendo establecer esta forma de sucesión sobre el tercio de legítima estricta, de manera que dicha persona será fiduciario ${ }^{72}$, quedando los restantes herederos en una posición de fideicomisarios ${ }^{73}$. De esta forma se pone en poder de la persona designada por el testador, una masa de bienes dirigida a proporcionar un rédito que permita a la misma tener una desenvoltura económica durante su vida, de manera que a su fallecimiento pasará a la propiedad del resto de los herederos designados en el fideicomiso. Esta situación solo es posible en el caso de que exista esta discapacidad, por lo que todos los bienes del testador pueden quedar sujetos a la misma hasta el momento en que fallezca y sigan el curso previsto para los fideicomisarios. En este caso se aplicarían las disposiciones tributarias que afectan a los patrimonios protegidos, de manera que gozarían de los beneficios fiscales que se describen a continuación. A partir de este momento el funcionamiento es similar, salvo en el caso de fallecimiento o pérdida de la condición de incapacidad; momento en el que dicho patrimonio, siguiendo su curso sucesorio queda en mano de los fideicomisarios y se produce la sucesión civil con la correspondiente eficacia tributaria.

Es necesario señalar que las personas a las que se les puede dotar con un patrimonio protegido, pueden tener, a su vez, un patrimonio sin estas características. Incluso ellas podrían ir dotando el patrimonio protegido, lo que supondría un beneficio fiscal, pero a su vez, una limitación de la capacidad de disponer del mismo, salvo para hacer frente a las eventualidades que señala la regulación de este patrimonio ${ }^{74}$.

La principal novedad con respecto a regulaciones anteriores es que no solo cabe la aportación de capitales, también se pueden aportar bienes, aunque existe la necesidad de que los mismos estén incardinados a satisfacer las necesidades de quien es titular del patrimonio. No existe duda cuando se trata de bienes que producen rentas económicas, en otro caso hay que estar a las limitaciones que la legislación contempla.

El tiempo transcurrido desde que se promulgó la ley ha permitido que la doctrina haya realizado comentarios interesantes al respecto, que van a servir de base para la elaboración de estos apuntes ${ }^{75}$.

\footnotetext{
${ }^{71}$ CV831/18 No se puede disponer del patrimonio protegido para necesidades corrientes en los cuatro años siguientes a su imposición mientras viva quien lo constituyó. Se trata de evitar la descapitalización del mismo.

${ }^{72}$ Cabría la opción en caso de una pluralidad de discapacitados de que fuesen cofiduciarios, o que uno de ellos fuese fiduciario y el siguiente el primer fideicomisario (Resolución DGRN de 26 de julio de 2003).

73 GARCIA MARTINEZ, C: "La sustitución Fideicomisaria en la Ley 41/2003 de 18 de noviembre de Protección de las personas con Discapacidad, su impacto Fiscal; Impuestos; documento 17; 2015; Instituto de Estudios Fiscales. En este trabajo se analizan aspectos como el fideicomiso de residuo, que sería el patrimonio resultante después de que el fiduciario realice las disposiciones necesarias sobre el mismo para atender sus necesidades cotidianas.

${ }^{74}$ DE HARO IZQUIERDO, M: Op. Cit; Pág. 4.

75 LUCAS DURAN, M; MARTÍN DEGANO, I: Los patrimonios protegidos de personas con discapacidad y su fiscalidad; IEF; Documento 4/2014; CUBILES SÁNCHEZ-POBRE, P: “La protección
} 
Solo los familiares hasta el tercer grado, incluyendo el cónyuge, pueden hacer aportaciones hasta el límite de $10.000 €$ anuales con un total para el perceptor de $24,250 €$, aunque el exceso solo tendrá la pérdida del beneficio, paro no la posibilidad de pérdida de su aportación. El propio aportante con discapacidad podrá llegar a la cifra de $24.250 €$ de forma personal, pero el límite en este caso será el mismo que en el caso general.

En caso de exceso de cantidades aportadas, pueden reducirse en los cinco ejercicios siguientes. Para un mejor cálculo de las cantidades que se van aportando, la Ley contempla la posibilidad de que inicialmente se minoren sobre el impuesto las cantidades pendientes de aportar de los ejercicios anteriores y finalmente se deduzcan las cantidades que se han aportado en el ejercicio en curso. En caso de exceso, se computan primero las cantidades que hayan aportado los propios discapacitados, posteriormente la de los que haya hecho aportaciones, teniendo en cuenta que se reducirán en proporción a la cantidad aportada por cada uno, dejando el exceso como cantidad a reducir en los ejercicios siguientes.

Pueden ser aportantes, tanto el propio incapaz, dando lugar a la reducción de la base imponible de su declaración por la cantidad aportada. Así mismo las aportaciones las pueden realizar parientes hasta el tercer grado e incluso las personas que hayan sido nombradas tutores o tengan al incapaz en régimen de acogimiento.

En todo caso los patrimonios protegidos tienen unos límites anuales de aportación, de manera que en caso de que la cantidad que se aporte sea superior a la máxima permitida pasará a regirse por las normas del impuesto de donaciones ${ }^{76}$.

4.2.2.1. Aportación dinerarias: Las aportaciones se efectúan como en un plan de pensiones, de forma sistemática y con unos máximos fijados en nuestra legislación. Estas aportaciones son deducibles en IRPF para quienes las aportan. Existen unos máximos que son $10.000 €$ por aportante de IRPF con un máximo de $24.250 €$. En caso de que los aportantes sean sujetos pasivos del IS, se deducen de dicho impuesto. En ambos casos se considera rendimiento del trabajo en el momento de su recuperación vía ingreso.

4.2.2.2. Aportación de valores: La aportación de este tipo de activos tiene una regulación similar a las aportaciones dinerarias y con los mismos límites que se dan en ellas. En ambos casos la posibilidad de fraccionar la entrega hace que no deba existir problema en el momento en que se hace la aportación.

4.2.2.3. Aportación de seguros: Las compañías de seguros se han preocupado para que dentro de las aportaciones pueda haber este tipo de bienes y para ello existen consultas vinculantes que lo amparan: V0989-0 $7^{77}$ de 21/05/2007 y V0991-07 ${ }^{78}$ de 25/05/2007.

patrimonial de las personas con discapacidad en la Ley 41/2003 de 18 noviembre”; Quincena Fiscal; n 5; 2005.

${ }^{76}$ En el caso andaluz existen unas reducciones por discapacidad en el caso de donaciones que se elevan a $47.858,59$ (> 33\%) o a 150.253,03 $€(>65 \%)$. Si bien tiene que cumplir los requisitos de parentesco que no se dan en IRPF.

${ }^{77}$ Es posible considerar como aportación a este tipo de patrimonios: 1) seguros de vida de rentas diferidas en las que el asegurado y beneficiario es la persona con discapacidad y el beneficiario en caso de fallecimiento es el aportante del patrimonio protegido. 2) contratos de seguro de riesgo, en el que el 
4.2.2.4. Aportación de derechos: En caso de aportación de derechos, cabe la posibilidad de que se ceda un derecho temporal, como ocurre con el arrendamiento o el usufructo $^{79}$. Existen consultas vinculantes que aprueban la posibilidad de aportar el usufructo de un inmueble V2475/08 de 21/12/2008.

4.2.2.5. Aportación de bienes inmuebles: Este tipo de bienes cumple plenamente la función que se espera de un patrimonio protegido. Sin embargo, esta situación se complica cuando el bien está hipotecado y es el receptor quien debe pagar la hipoteca, pues puede ser que la carga suponga una merma del resto del patrimonio.

4.2.2.6. Extinción del patrimonio protegido: La forma normal de extinguir un patrimonio protegido es a través de su recuperación por la vía del cobro, que estará sujeto al IRPF, si bien en el caso de personas con discapacidad solo se integrarán en dicho impuesto cuando el importe supere la cantidad de tres veces el IPREM (indicador público de renta de efectos múltiples), que, en los últimos años y que se mantiene de 2019, ha sido de 22.558,77€. Puede ocurrir que quien es titular del patrimonio protegido, fallezca. En ese caso se aplican las leyes de sucesión, tanto de forma civil como tributaria. Puede que deje la persona de ser discapacitada, se aplican las normas tributarias para cualquier otro tipo de patrimonio.

En caso de que sea dispuesto por el discapacitado, estará supervisada la administración por el Ministerio Fiscal, quien puede actuar si lo estima conveniente. Se considerará rendimientos del trabajo ${ }^{80}$ o del tipo de capital de que se trate. En caso de que proceda de herencia, tributará de acuerdo a las normas de este impuesto, aunque los rendimientos lo serán de IRPF ${ }^{81}$.

\subsection{Ayudas Autonómicas.}

Dentro de la libertad de cada autonomía para modificar el IRPF, se ha ido modificando el sistema de ayudas estatal, en unos casos para mejorarlas, en otros para crear una configuración propia, que saldrá del tramo autonómico del impuesto, de manera que la igualdad se va difuminando para dar paso a un concepto de fiscalidad territorial.

Andalucía: DL 1/2018 de 19 de junio que aprueba el Texto Refundido de las disposiciones de la Comunidad Autónoma en materia de tributos cedidos.

\footnotetext{
asegurado es el aportante al patrimonio protegido y el beneficiario, la persona con discapacidad. 3) Contratos de rentas inmediatas, en el que el asegurado y beneficiario es la persona con discapacidad y beneficiario el aportante. 4) contratos de capital diferido en el que el asegurado y beneficiario del capital diferido es la personal con discapacidad y el beneficiario el aportante.

78 Se trata de rentas vitalicias inmediatas, constante y mensual en doce pagos para supervivencia. El tomador es el padre de la persona con discapacidad que lo abona en prima única, el asegurado y beneficiario la persona con discapacidad y beneficiario el aportante por la parte no consumida.

79 MARIN CALERO, C.: La integración jurídica y patrimonial de las personas con discapacidad psíquica o intelectual; Editorial universitaria Ramón Areces; Madrid; 2005.

${ }^{80}$ Están exentos hasta 3 veces el IPREM, en la actualidad está en 22.365,44€

${ }^{81}$ GUERRA REGUERA, M: “Los patrimonios protegidos; cit; Págs. 9 y ss.
} 
Art. 11. Deducción autonómica IRPF por contribuyente con discapacidad. $100 €$ cuando la base imponible no supere los $19.000 €$ en individual o $24.000 €$ en conjunta.

Art. 12. Deducción autonómica IRPF para contribuyentes con parejas con discapacidad. $100 €$ en las mismas circunstancias anteriores, aunque son incompatibles.

Art. 13. Deducción autonómica por asistencia a personas con discapacidad. $100 €$ siempre que se acredite y se pague más de esa cantidad a la seguridad social.

Aragón: DL 1/2005, de 26 septiembre, aprueba el texto refundido de las disposiciones dictadas en materia de tributos cedidos.

Art. 110-3. Deducción de la cuota íntegra autonómica del IRPF en atención al grado de discapacidad de alguno de los hijos. $200 €$ por hijo nacido en el periodo.

Art. 110-5. Deducción de la cuota íntegra autonómica del IRPF por el cuidado de personas dependientes. $150 €$, se trata de personal de al menos 65 años.

Canarias: DL 1/2009, de 21 de abril, por el que se aprueba el Texto Refundido de las disposiciones legales vigentes dictadas en materia de tributos cedidos.

Art. 9. Deducción por donaciones para adquisición o rehabilitación de primera vivienda habitual. $2 \%$ de la cantidad donada cuando se trate de discapacitados.

Art. 11. Deducción por contribuyentes con discapacidad y mayores de 65 años. $300 €$

Art. 14.ter. Deducción por obras de adecuación de la vivienda habitual por razón de discapacidad. $10 \%$ de las cantidades satisfechas.

Art. 16. quater. Deducción por familiares dependientes con discapacidad. 500 $€$ Solo cuando es superior al 65\%, limitada a un máximo de rentas.

Cantabria: DL 62/2008, de 19 de junio, por el que se aprueba el texto refundido de la Ley de Medidas Fiscales en materia de Tributos cedidos por el Estado.

Art. 2.1. Por Arrendamiento de vivienda habitual para personas con discapacidad. $10 \%$ de las cantidades, con un máximo de $300 €$ (declaración individual menor de 22.000€) o 600€ (declaración conjunta $31.000 €$ ) y para discapacidad superior al $65 \%$

Art. 2.2. Por cuidado de familiares con minusvalía superior al $65 \%$. $100 €$

Art. 2.4. Por donativos a fundaciones o al Fondo Cantabria Coopera o a asociaciones que persigan entre sus fines el apoyo a personas con discapacidad. El 15\% de las cantidades donadas a este tipo de entidades que estén domiciliadas en Cantabria.

Castilla La Mancha: Ley 8/2013, de 21 de noviembre, de Medidas Tributarias de Castilla-La Mancha.

Art. 2. Deducción por familia numerosa y con discapacidad de uno de sus miembros de más del $65 \%$, se deduce $300 €$, 900€ en categoría especial. Limitada en los ingresos a $27.000 €$ en declaración individual y $36.000 €$ en declaración conjunta. 
Art. 4. Deducción por discapacidad > 65\% del contribuyente. $300 €$ mismos límites

Art. 5. Deducción por discapacidad de ascendientes o descendientes. Igual que art. 4.

Art. 8. Deducción por acogimiento no remunerado de mayores de 65 años o discapacitados superior al 33\% 600€. Límites $12.500 €$ y $25.000 €$

Art. 10. Deducción por cantidades donadas para la ayuda a personas con discapacidad. $15 \%$ de lo donado a entidades inscritas en Castilla-La Mancha.

Castilla León: DL 1/2013, de 12 de septiembre, por el que se aprueba el texto refundido de las disposiciones legales de esta Comunidad en materia de tributos propios y cedidos.

Art. 6. Deducción por discapacidad. Varía de acuerdo a la edad: $>65$ años $300 €$ más del 33\% y $656 €$ más de $65 \%$. <65 años 300€ más del 65\%. Límites: 18.900 y $31.500 €$.

Art. 7.2. Inversión en adaptación de vivienda para personas con discapacidad, $15 \%$ de la cantidad invertida inferior a $20.000 €$ Administrativas.

Cataluña: Ley 31/2002, de 30 de diciembre, de Medidas Fiscales y

Art. 1.1. Deducción por alquiler de la vivienda habitual para discapacitados con más del 65\%. 10\% del alquiler con límite en $300 €$

Madrid: DL 1/2010, de 21 de octubre, del Consejo de Gobierno, por el que se aprueba el Texto Refundido de las Disposiciones Legales de la Comunidad de Madrid en materia de tributos cedidos por el Estado.

Art. 7. Deducción por acogimiento no remunerado de mayores de sesenta y cinco años y/o discapacitados. 900€. Límite 25.620 y $36.200 €$

Art. 10. Deducción por el incremento de los costes de la financiación ajena para la inversión en vivienda habitual derivado del alza de los tipos de interés.

Valencia: Ley 13/1997, de 23 de diciembre, regula el tramo autonómico del Impuesto sobre la Renta de las Personas Físicas y restantes tributos cedidos.

Art. 4. Uno.c) Por nacimiento o adopción, durante el período impositivo, de un hijo discapacitado físico o sensorial, con un grado de minusvalía igual o superior al 65 por 100 , o psíquico, con un grado de minusvalía igual o superior al 33 por 100. 224 o 275€, dependiendo si son uno o dos los hermanos. Límite: 25.000 y $40.000 €$

Art. 4. Uno.g) Para contribuyentes discapacitados de más de 65 años. $179 €$

Art. 4. Uno.h) Por ascendientes mayores de 75 años, y por ascendientes mayores de 65 años que sean discapacitados físicos o sensoriales, con un grado de minusvalía igual o superior al 65 por 100, o discapacitados psíquicos. $179 €$

Art. 4. Uno.l) Por cantidades destinadas a la adquisición de vivienda habitual por discapacitados físicos o sensoriales, con un grado igual o superior al 65 por 100, o psíquicos, con un grado de minusvalía igual o superior al 33 por $100.5 \%$ de la cantidad 
Art. 4. Uno.n) Por arrendamiento de la vivienda habitual, de menores de 35 años con discapacidad de más del 33\% el 25\%. Si es mayor de 35 años, el 20\%. Límite 23.000 y $37.000 €$.

Extremadura: DL 1/2018, de 10 de abril, por el que se aprueba el texto refundido de las disposiciones legales en materia de tributos cedidos por el Estado.

Art. 5. $150 €$ en Deducción autonómica por cuidado de familiares discapacitados con un grado de discapacidad igual o superior al 65\% o que esté judicialmente incapacitado.

Art. 9. $300 €$ de deducción autonómica por arrendamiento de vivienda habitual para personas con discapacidad con un grado reconocido igual 0 superior al $65 \%$, o esté judicialmente incapacitado.

Galicia: DL 1/2011, de 28 de julio, por el que se aprueba el texto refundido de las disposiciones legales en materia de tributos cedidos por el Estado.

Art. 5. Seis. Deducción por sujetos pasivos discapacitados, de más de 65 años, que precisen ayuda de terceras personas. 10\% con límite el $600 €$. Límite 22.000 y $31.000 €$

Baleares: DL 1/2014, de 6 de junio, por el que se aprueba el Texto Refundido de las Disposiciones Legales en Materia de Tributos Cedidos por el Estado.

Art. 2. Incremento del mínimo personal y familiar.

Art. 3 bis. Deducción autonómica por el arrendamiento de la vivienda habitual en el territorio de las Illes Balears a favor de determinados colectivos. $15 \%$, máximo de $400 €$.

Art. 6. Deducción autonómica para los declarantes con discapacidad física, psíquica o sensorial o con descendientes con esta condición. 150€ para discapacidad psíquica.

La Rioja: Ley 10/2017, de 27 de octubre, por la que se consolidan las disposiciones legales en materia de impuestos propios y tributos cedidos.

Art. 31.bis Modificación del mínimo por descendientes discapacitados.

Disposición transitoria primera. d) 15\% de deducción por las cantidades invertidas durante el ejercicio en obras de adecuación de vivienda habitual en La Rioja para personas con discapacidad.

Asturias: DL 2/2014, de 22 de octubre, por el que se aprueba el Texto Refundido de las disposiciones legales en materia de tributos cedidos por el Estado.

Art. 4. Deducción por adquisición o adecuación de vivienda habitual en el Principado de Asturias para contribuyentes con discapacidad. 3\% de la cantidad satisfecha.

Art. 5. Deducción por adquisición o adecuación de vivienda habitual para contribuyentes con los que convivan sus cónyuges, ascendientes o descendientes con discapacidad. 3\% de la cantidad satisfecha.

\subsection{Ayudas Municipales.}

Existen multitud de exenciones, reducciones y modificaciones que afectan en el ámbito local a las personas con discapacidad. Su sistematización resulta imposible, pues cada Ayuntamiento ha regulado a través de las ordenanzas fiscales las que ha creído convenientes, pero no está de más enumerar algunas de las más habituales, de 
manera que cada persona pueda comprobar en las ordenanzas fiscales de su municipio, si está afectado con alguna de los beneficios fiscales que otorga el mismo.

- IBI. El TRLHL no incluye ninguna reducción o bonificación obligatoria por este concepto. Lo que no supone que existan ayuntamientos que hayan decidido reducirlo en función de la discapacidad del sujeto pasivo.

- IAE. El art. 82.f. TRLHL incluye exenciones objetivas para las asociaciones sin ánimo de lucro que realicen actividades económicas, entre las que se incluyen las de personas con diversidad funcional. Cabría también la reducción de la cuota para las empresas que generen empleo que se incrementa en los discapacitados.

- IVTM. Están exentos de este impuesto los vehículos que lo estén a efectos del IDMT, así como los matriculados a nombre de minusválidos para su uso exclusivo ${ }^{82}$. Cabe la posibilidad de solicitar la exención de los periodos no prescritos en el caso en que no se conociese esta exención ${ }^{83}$, incluso cuando se trate de cotitularidad ${ }^{84}$.

- IIVTU. Los incrementos puestos de manifiesto por la cesión de terrenos de forma gratuita a entidades sin ánimo de lucro que tengan la calificación de benéfico-docentes, están exentas de pagar este impuesto. Una forma de incentivarlas.

- Permiso para estacionamiento concreto en la vía pública. Los llamados aparcamientos reservados para "minusválidos", donde solo se atiende al grado y no al tipo, aunque en muchos casos no le impida en la movilidad.

- Ayudas para el transporte público o descuento en los mismos.

- Descuento para actividades de tipo lúdico, deportivo o de ocio.

\subsection{Beneficios fiscales para la contratación laboral en personas con incapacidad}

\subsubsection{Reconocimiento de la discriminación en el ámbito laboral.}

La discapacidad está menos reconocida en este ámbito, el propio Estatuto de los Trabajadores reconoce que existe una falta de aptitud en estas personas para desempeñar determinados puestos de trabajo situación que se reproduce en el acceso a la función pública donde se admite como requisito "no padecer enfermedad o defecto físico que impida el desempeño de las funciones correspondientes”. Afortunadamente existen otras disposiciones que van en sentido contrario, pero no estaría de más que nuestras leyes marco, cambiases este tipo de texto, que sirve para mantener la discriminación ${ }^{85}$.

Las medidas de fomento del empleo, pueden agruparse en medidas pasivas, que son las que aquí se concretan en ayudas, beneficios fiscales y que se completarían con las prestaciones que se puedan conceder y que depende de la voluntad de quienes

\footnotetext{
82 FERNANDEZ JUNQUERA, M: “Tributación de los vehículos de o para personas de movilidad reducida. Especial consideración de las ambulancias colectivas”; Quincena Fiscal; nº 6; 2012; Pág. 5.

${ }^{83}$ CPR 2011/71

${ }^{84}$ CPR 2011/72

85 “2006-2016: diez años de la convención internacional sobre los derechos de las personas con discapacidad - balance de su aplicación en España. CERMI 2017. Pág. 276.
} 
contratan a personas de estas características, que son los beneficiarios de la ayuda. Por otro lado, están las medidas activas, que se estudian más adelante ${ }^{86}$.

\subsubsection{Incremento de plantilla de trabajadores con discapacidad.}

Dentro del Impuesto de Sociedades, aplicable al IRPF en actividades económicas (art 38 LIS 2014 de acuerdo con el art 26.3 Ley 14/2003 de 27 de septiembre que elimina la exigencia de que sea por tiempo indefinido), existe una deducción en la cuota íntegra de $9.000 €$ por incremento de plantilla de personas con discapacidad, que se amplía a $12.000 €^{87}$ en el caso de que la discapacidad sea superior al $65 \%^{88}$.

Al tratarse de incremento, supone que el promedio se mantenga para seguir gozando de este beneficio fiscal ${ }^{89}$; y que además existe incremento general de empleo. Esta deducción es de una importancia enorme, pues supone una posibilidad de reducir los impuestos de un beneficio entre $36.000 €$ y $48.000 €$.

4.5.3. Reducción de los módulos en contratación de personas con discapacidad.

La contratación de personas con discapacidad para aquellos empresarios que están en régimen de estimación objetiva, hace que el importe por personal asalariado solo se compute al $40 \%$, lo que supone un estímulo interesante para quien tenga opción de contratar a una persona en estas condiciones ${ }^{90}$.

\subsection{Beneficios en el impuesto de Transmisiones Patrimoniales, AJD y OS:}

Igualmente, en los impuestos cedidos, se ha admitido la posibilidad de modificar las reducciones y bonificaciones, lo que ha permitido que determinadas autonomías hayan decidido mejorar ciertas condiciones de los mismos.

Andalucía: (DL 1/2018, de 19 de junio)

Art. 35. Tipo de gravamen reducido para promover una política social de vivienda.

Art. 40. Tipo de gravamen reducido para promover una política social de vivienda.

Aragón: (DL 1/2005, de 26 septiembre)

\footnotetext{
${ }^{86}$ SANTERO, R; CASTRO, B; MARTINEZ, I; GULLÓN, N: “integración de personas con discapacidad en la Economía Social. Elementos facilitadores y obstáculos detectados en la incorporación del colectivo"; CIRIEC-España- revista de economía pública, social y cooperativa; nº 88; 2016; Pág. 35.

${ }^{87}$ CPR 2016/214

${ }^{88}$ ROMERO FLOR, L.M; ALAMO CERRILLO, R: "Incentivos fiscales al emprendimiento"; Quincena Fiscal; nº 17; 2014; Pág. 9

${ }^{89}$ MARTINEZ-CARRASCO PIGNATELLI, JM: "Deducciones en la cuota tributaria del Impuesto sobre Sociedades”; Quincena Fiscal; n 21; 2015; Pág. 15.

${ }^{90}$ CPR 2016/5219
} 
Art. 121.4. Bonificación en cuota aplicable a la adquisición de su vivienda habitual por parte de personas físicas incluidas en determinados colectivos.

Art. 122.8. Tipo impositivo para actuaciones de eliminación de barreras arquitectónicas y adaptación funcional de la vivienda habitual de las personas con discapacidad igual o superior al 65\%.

Art. 122.10. Bonificación en cuota aplicable a la adquisición de su vivienda habitual por parte de personas físicas incluidas en determinados colectivos.

Baleares: (DL 1/2014 de 6 de junio) 3\% cuando el adquirente tenga 65\%

Canarias: (DL 1/2009, de 21 de abril)

Art. 33. Tipo de gravamen reducido al $4 \%$ en la adquisición de vivienda habitual por personas con discapacidad.

Art 37. Tipo 0,4\% AJD de discapacitados.

Cantabria: (DL 62/2008, de 19 de junio)

Art. 9.3.b. Tipos de gravamen reducido al 5\% aplicables en las transmisiones patrimoniales onerosas de bienes inmuebles.

Art. 13.4 AJD reducido al 0,3\% vivienda habitual de minusválido

Cantabria: (DL 62/2008, de 19 de junio)

Art. 9. Tipos de gravamen aplicables en las transmisiones patrimoniales onerosas de bienes inmuebles.

Castilla y León: (DL 1/2013, de 12 de septiembre)

Art. 25. Tipos incrementados y reducidos al $5 \%$ en la modalidad de Transmisiones Patrimoniales Onerosas

Art. 26. Tipos incrementado y reducidos en la modalidad de Actos Jurídicos Documentados.

Art. 28. Aplicación de los tipos impositivos reducidos.

Cataluña: (Ley 31/2002, de 30 de diciembre)

$5 \%$ en adquisición de vivienda por discapacitado.

Valencia: (Ley 13/1997, de 23 de diciembre)

Art. 13. Cuatro. 3). Transmisiones Patrimoniales Onerosas reducido al $4 \$$.

Art. 14.1 AJD 0,1\% en Hipotecas vivienda habitual discapacitados.

Disposición adicional sexta. Reglas relativas a los discapacitados.

Extremadura: (DL 1/2018, de 10 de abril)

Art. 41.1.c). Bonificación autonómica del 20\% de la cuota en la adquisición de vivienda habitual para contribuyentes con un grado de discapacidad igual o superior al $65 \%$, o acredite necesitar ayuda de terceros para desplazarse, o tenga reconocida movilidad reducida, o haya sido declarado judicialmente incapacitado

Galicia: (DL 1/2011, de 28 de julio)

Art. 14. Tipo de gravamen reducido al $4 \%$ en la modalidad de transmisiones patrimoniales onerosas.

Tres. Tipo de gravamen para la adquisición de vivienda habitual por discapacitados.

Art. 15. Tipo de gravamen en la modalidad de actos jurídicos documentados. 
Tres. Tipo de gravamen reducido al 4\% aplicable en la adquisición de vivienda habitual por discapacitados y en la constitución de préstamos hipotecarios destinados a su financiación.

Art. 16. Deducciones y bonificaciones en la cuota íntegra en la modalidad de transmisiones patrimoniales onerosas.

Siete. Deducción por adquisición de vivienda habitual por personas con discapacidad, familias numerosas y menores de 36 años en áreas rurales.

Art. 17. Deducciones y bonificaciones en la cuota íntegra en la modalidad de actos jurídicos documentados

Ocho. Deducción por adquisición de vivienda habitual y por constitución de préstamos hipotecarios destinados a su financiación, por personas con discapacidad, familias numerosas y menores de 36 años, en áreas rurales.

La Rioja: (Ley 10/2017, de 27 de octubre)

Art. 45. Tipos impositivos reducidos al 5\% en la adquisición de vivienda habitual.

Art. 49. Tipo impositivo reducido y deducción en la cuota para los documentos notariales de adquisición de vivienda para destinarla a vivienda habitual.

\subsection{Beneficios para la incapacidad a efectos del Impuesto sobre el Patrimonio.}

Andalucía: (DL 1/2018, de 19 de junio)

Art. 18. Mínimo exento para los contribuyentes con discapacidad.

Aragón: (DL 1/2005, de 26 septiembre)

Art. 150.1. Bonificación de los patrimonios especialmente protegidos de contribuyentes con discapacidad.

Canarias: (DL 1/2009, de 21 de abril)

Art. 29.bis. Exención de los patrimonios especialmente protegidos de los contribuyentes con discapacidad.

Castilla y León: (DL 1/2013, de 12 de septiembre)

Art. 11. Exención de los patrimonios especialmente protegidos de contribuyentes con discapacidad.

Valencia: (Ley 13/1997, de 23 de diciembre).

Art. 8. Mínimo exento

Extremadura: (DL 1/2018, de 10 de abril)

Art. 14. Mínimo exento general y para discapacitados.

Asturias: (DL 2/2014, de 22 de octubre)

Art. 16. Bonificación de los patrimonios especialmente protegidos de contribuyentes con discapacidad. 


\subsection{Beneficios a efectos del Impuesto de Sucesiones y Deducciones para personas con discapacidad.}

Ya se ha comentado que son las leyes civiles las que han de regular esta situación. De partida los bienes colacionables en derecho de sucesiones de carácter civil afectos al pago de alimentos, por lo que necesariamente quedarían exentas las cantidades mencionadas ${ }^{91}$.

Otra opción es reforzar el testamento hacia las personas con discapacidad, frente a quienes no la tienen. En estas sucesiones existe una reducción singular de $47.858,59 €$ (>33\% y >65\%) y $150.253,03 €(>65 \%)$

En caso de muerte de la persona con discapacidad se puede generar una prestación por derecho de viudedad u orfandad a favor de quien haya hecho las aportaciones a la persona con discapacidad, pero solo en proporción a la aportación que hayan hecho estos aportantes. Estas cantidades no estarán sujetas al impuesto de sucesiones y donaciones (art. 53.3 LIRPF).

En cuanto a las deducciones autonómicas referentes al Impuesto sobre Donaciones, generalmente se aplica una exención entre el 95\% y el 99\% cuando se trata de discapacitados de $>65 \%$. Este tipo de bonificaciones cambian con frecuencia, por lo tanto, es importante saber que existen, pero acudir a las mismas en el caso en que haya de aplicarse para comprobar el estado del momento.

Andalucía: (RDL 1/2018 de 19 de junio) Art. 28. Reducción para personas con discapacidad: $180.000 €$, aunque en caso de recibir más de una donación, se sumarán a efectos determinas esta reducción.

Aragón.: (RD 1/2005 de 26 septiembre) art. 131.2. 100\% de reducción de las adquisiciones hereditarias para discapacitados de más del 65\%.

Asturias: (DL 2/2014 de 22 de octubre) arts. 19 y 20. 100\% de reducción de las adquisiciones hereditarias para discapacitados de más del $65 \%$.

Baleares: (DL 1/2014 de 6 de junio) arts. 22 y 23. Reducción de $48.000 €$ (>33\%) y $300.000 €(>65 \%)$

Canarias: (Ley 4/2012 de 25 junio) Art. 46. Se aplica una reducción de $72.000 €(>33 \%)$ o del $400.000 €(>65 \%)$

Cantabria: (DL 63/2008 de 10 junio) art. 5. Reducción 50.000 y 200.000 $>33 € \mathrm{y}>65 \%$

Castilla - La Mancha: (Ley 8/2013 de 21 noviembre) art. 15. Reducción $125.000 €$ y $225.000 €>33 €$ y $>65 \%$

Castilla León: (DL 1/2013 de 12 septiembre) art. 12 y 19. Reducción $125.000 €$ y $225.000 €>33 €$ y $>65 \%$

Cataluña: (Ley 19/2010 de 7 junio) art. 3. Reducción $275.000 €$ y 650.000€ $>33 €$ y $>65 \%$

Extremadura: (DL 1/2013 de 21 mayo) art. 15 y 17. Reducción $175.000 €$ $>33 €$ en donaciones y $60.000,120.000$ y $180.000 €>33 \%$, >50\% y >65\%

Galicia: (DL 1/2011 de 28 junio) art. 6.3. Reducción $150.000 €$ y 100\% >33€ $\mathrm{y}>65 \%$

\footnotetext{
${ }^{91}$ LEÑA FERNANDEZ, R: "Posibilidades testamentarias y otras disposiciones en materia de sucesiones que ofrece la Ley 41/2003”; Los derechos de las personas con discapacidad; Vol. II; Aspectos económicos y patrimoniales; Consejo General del Poder Judicial; Madrid; 2007.
} 
Comunidad de Madrid: (Dl 1/2010 de 21 octubre) art. 21.1. Reducción $55.000 €$ y $153.000 €>33 €$ y $>65 \%$

Región de Murcia: (DL 1/2010 de 5 noviembre) art. 3.2.2. Reducción $300.000 €$ y $450.000 €>33 €$ y $>65 \%$

Comunidad Valenciana: (Ley 13/1997 de 23 diciembre) art. 10. Reducción $120.000 €$ y $240.000 €>33 €$ y $>65 \%$

\section{9.- Beneficios en el IVA por motivo de la incapacidad}

La regulación del IVA recoge algunas reducciones de tipo para casos concretos y no todos son aplicables a las discapacidades psíquicas.

- Las prestaciones de asistencia social están exentas de IVA (art. 20.1.8 LIVA), de manera que todos los servicios prestados por este concepto no están gravados con este impuesto

- IVA reducido del 4\% para los vehículos que se dediquen habitualmente al transporte de personas minusválidas o en silla de ruedas, siendo suficiente que se justifique el destino del vehículo ${ }^{92}$.

- Cualquier tipo de aparato o complemento dedicado a mejorar la vida de las personas con discapacidad, tributa al $4 \%$, entre las que se pueden encontrar gafas y lentillas que por norma tributan al 10\%. Cabría aplicar este IVA a los artículos pedagógicos concretos que se destinan a esta finalidad.

\subsection{Beneficio a efecto de las leyes de Impuestos Especiales}

Existen reducciones impositivas cuando se trata de adquirir vehículos para personas con discapacidad, consistentes en la reducción o eliminación del impuesto de matriculación. Aunque en este caso hace referencia a movilidad reducida, precisamente para dar estas ayudas solo a quienes tengan este tipo de discapacidad específica. No parece posible su uso para aquellos que no tienen esta necesidad ${ }^{93}$.

Es posible que la concesión de esta ayuda suponga problemas en cuanto el vehículo lo adquiere quien carece de ingresos para ello, lo que puede suponer una presunción de ingresos para el adquirente, lo que obliga a realizar una donación, o cualquier otro acto jurídico de transmisión, al discapacitado para que pueda realizar la adquisición del vehículo.

\section{AYUDAS EN EL ÁMBITO LABORAL}

Es necesario comenzar diciendo que la incapacidad, bien temporal o permanente, tiene un tratamiento concreto en la regulación de la Seguridad Social, que tienen una clasificación propia en relación a la imposibilidad de desempeñar tareas laborales $^{94}$. Tiene una protección específica que no entraría en este estudio, salvo que se convierta en discapacidad de tipo psicológico a la que se aplicarían todas las ventajas

\footnotetext{
${ }^{92}$ CV718/16 es necesario la previa declaración de discapacidad y que la reconozca la AEAT.

93 FERNANDEZ JUNQUERA, M Op. Cit; Pág. 3.

94 Por la facilidad de localización, a quien tenga interés en conocer más POLONIO DE DIOS, G: La discapacidad desde la perspectiva del Estado Social; Tesis doctoral defendida en la Universidad de Córdoba dirigida por M. ${ }^{a}$ Carmen Mingorance Gosálvez; 2005; págs. 290 a 304.
} 
comentadas, con independencia de la que le corresponda por ser de carácter laboral en general.

Pero aún queda mucho por hacer desde la Responsabilidad Social Corporativa, donde entrarían las empresas privadas a contribuir a la mejora de las condiciones de trabajo de las personas con discapacidad, e incluso a la aportación económica a causas sociales. Para ello es importante la actuación del Estado en cuanto a las ayudas de todo tipo que aporte a estas empresas por su colaboración en esta materia ${ }^{95}$.

\subsection{Reserva de empleos públicos y privados para personas con discapacidad.}

La principal ventaja reconocida es la reserva de determinado porcentaje de los empleos públicos a los minusválidos, que se eleva al 5\%, que muchas veces se materializa en reservas de cupo para oposiciones y concursos, para los que suele haber reducción o exención de tasas en dichos procesos.

En el caso de las empresas privadas de más de 50 trabajadores, se supone que también existe esta opción cifrada en un $2 \%$, si bien depende del convenio colectivo o a la voluntad del empresario que puede aplicar medidas alternativas; aunque no existen estadísticas que hablen del cumplimiento de esta normativa ${ }^{96}$

\subsection{Reducción de cuotas de la Seguridad Social.}

La reducción de cuotas de la Seguridad Social en el caso de discapacidad es otra de las ventajas que las empresas que contratan a este tipo de personas con discapacidad psíquica, parálisis cerebral o enfermedad mental; cuentan en cuanto al coste que estos suponen y la supuesta mejor opción que sería este tipo de contratación ${ }^{97}$.

En el caso de la minusvalía psíquica se admite desde el 33\% como discapacidad severa, frente a la discapacidad física que exige el $65 \%$.

Si se trata de contrato indefinido, las bonificaciones de $5.100 €$ para el hombre y $5.950 €$ para la mujer, si son menores de 45 años (discriminación positiva) y de $6.300 €$ en caso de que sean mayores de esta edad.

En caso de contrato temporal para fomento de empleo, la bonificación es de, dependiendo si son hombres o mujeres: $4.100 €$ y $4.700 €$ en menores de 45 años; $4.700 €$ y $5.300 €$ en mayores de 45 años.

En los contratos de interinidad con desempleados con discapacidad para sustituir a trabajadores con discapacidad, la bonificación es del $100 \%$ de las cuotas empresariales.

En el caso de trabajadores que coticen por el Régimen de Autónomos (RETA) se reduce $60 €$ durante 12 meses al cotizante, que se amplía a 24 meses en el caso de que sea en municipios inferiores a 5.000 habitantes. En caso de que opten por una base de cotización mayor a la que le corresponde, se reduce el $80 €$ de la cuota durante los 12

\footnotetext{
${ }^{95}$ BLAZQUEZ LYDOY, I: "La responsabilidad social corporativa y la necesaria revisión del gasto no deducible en la Ley del Impuesto sobre Sociedades (Ley 27/2014); La dimensión social de la fiscalidad: discapacidad, tercer sector y mecenazgo; CERMI; 2017; págs. 241 a 278.

96 SANTERO, R; CASTRO, B; MARTINEZ, I; GULLÓN, N: Op. Cit; Pág. 35.

${ }^{97}$ Existe un folleto de bonificaciones/reducciones a la seguridad social de trabajadores con discapacidad que edita el SEPE (servicio público de empleo estatal).
} 
primeros meses. Se pueden ampliar las ayudas durante 48 meses más con una bonificación del 50\% de la cuota por contingencias comunes.

\subsection{Ayudas a las empresas privadas para adaptación de los puestos de trabajo.}

Este tipo de ayudas solo afectan a aquellos puestos que necesiten una adaptación especial, que suele ocurrir en aquellos casos en los que, por cuestiones de ergonomía, movilidad, o funcionalidad, sea necesario.

Tal vez una de las ventajas de este tipo sea la posibilidad de reducción de las jornadas de trabajo, con una ayuda para el trabajador, que puede dar una opción interesante para el empresario que ve cómo puede reducir esta actividad que el consiguiente ahorro para el empresario, sin menoscabo para el trabajador.

Otra de las ventajas es la suspensión del contrato por nacimiento de hijo en el caso de trabajadores discapacitados.

Andalucía tiene una ayuda de $8.800 €$ cuando se transforme un contrato temporal en indefinido a jornada completa si el contratado es discapacitado; o cuando se contrata directamente del desempleo para personas que lleven más de seis meses dadas de alta.

Murcia subvenciona el fomento de la inclusión laboral de las personas con discapacidad $^{98}$ : Para aquellas con un índice superior al 33\% a los que se les ayuda para: Integración en Centros Especiales de Empleo, Formas Innovadoras de integración laboral, Integración laboral de personas con discapacidad en el mercado de trabajo.

\subsection{Creación de centros especiales de empleo.}

El RDL 1/2013 de 29 de noviembre prevé la figura de los CEE para la inclusión de las personas con discapacidad, así como los Centros Ocupacionales. Al menos el $70 \%$ debe ser personas con discapacidad. Debe estar calificado por la administración. Se puede crear por particulares o por la administración ${ }^{99}$. En todo caso otra de las ventajas que tienen este tipo de centros es que se bonifica el $100 \%$ de las cuotas empresariales a la seguridad social por todos los conceptos.

Se plantearon como un paso intermedio para la inclusión, aunque en la actualidad se han quedado como centros de "empleo refugio". Se basa en beneficios fiscales y en subvenciones en función del empleo creado. Pero de esta forma crean puestos de trabajo. Este tipo de empresas trabajan en multitud de sectores y para ellas es más importante facilitar empleos de cualquier tipo a discapacitados, que buscar un sector laboral concreto. La actuación de este tipo de empresas está analizada en el caso de empresas de economía social (cooperativas y sociedades laborales) y el resultado es plenamente satisfactorio ${ }^{100}$. Entre las medidas fiscales que les benefician ${ }^{101}$ :

$$
\text { - Exención en el IAE }{ }^{102} \text {. }
$$

\footnotetext{
98 Leg_Orden de 8 junio 2016_LRM_2016_162

99 ARROYO COLOMA, M: La discapacidad en el sistema tributario; Tesis Doctoral, dirigida por el Catedrático Carlos María López Espadafor, defendida en la universidad de Jaén en 2017; Págs. 176 a 181.

100 SANTERO, R; CASTRO, B; MARTINEZ, I; GULLÓN, N: Op. Cit; Págs. 42 a 53.

101 MENDEZ TERROSO, I: “Incentivos fiscales de los Centros Especiales de Empleo”; Revista del Ministerio de Trabajo y Asuntos Sociales; n 56. Págs. 123 a 134

102 Ley 39/1988, art. 83.
} 
- Deducción por creación de empleo de personas con discapacidad.

- Deducción por adaptación de vehículos.

- Deducción por aportación a patrimonios protegidos.

- Exención en IS de los incrementos de patrimonio.

Por contrario, están sometidos a un control estricto en el cumplimiento de sus obligaciones y de los trabajadores de los mismos, en cuanto beneficiarios de ayudas de la administración que deben cotejarse debidamente. También existe una obligación de realizar una aportación para la constitución de una fundación ${ }^{103}$.

\subsection{Centro Ocupacional ${ }^{104}$}

RD 2274/1985 de 4 de diciembre, arts. 5 y 6, que regulan estos centros. Pensado para integrar a las personas con discapacidad, se dedican principalmente a la formación social y ocupacional y como tránsito para lograr la inclusión de las personas en los CEE. Están exentos de impuestos y si obtienen rentas por la venta de sus productos, el beneficio tributa al $10 \%$.

\subsection{Ayudas al autoempleo.}

Tal vez sea de los aspectos en los que más se puede evolucionar, pues son pocas las normas que inciden en este apartado ${ }^{105}$. La incorporación de una persona en esta situación al mundo laboral tiene un efecto multiplicador de ingresos para el Estado y de ahorro de ayudas, por lo que el beneficio a largo plazo es indiscutible.

Desde el SEPE (Servicio Estatal Público del Empleo) se conceden ayudas para el autoempleo (10.000 €), así como para formación (9.000 €) o asistencia técnica (2.000 $€)$ aunque están condicionadas al cumplimiento de ciertos requisitos. Este tipo de ayudas también pueden ser de tipo privado, como las que convoca la Fundación ONCE que oscilan entre los $3.000 €$ y $18.000 €^{106}$.

\section{CONCLUSIONES}

Que es mucho el camino recorrido en este ámbito del reconocimiento de las discapacidades psíquicas, es indudable. Que es mucho el camino que queda por recorrer, imaginable. Pero que hay que dotar a la sociedad de mecanismos reales de protección de los discapacitados, y hacer consciente al resto de que puede colaborar en esta tarea.

La discapacidad física y sensorial, ya había encontrado su lugar dentro del mundo de la diversidad que ha hecho al derecho entender que todos no somos iguales, que son necesarias los planteamientos tuitivos en los casos en que actuar de otra forma puede suponer una discriminación para quienes sufren este tipo de problemas.

\footnotetext{
${ }^{103}$ Ley 50/2002 en su art. 11 y en relación con la Ley 49/2002 se habla de realizar una aportación de $30.000 €$ para constituir la fundación mencionada.

${ }^{104}$ ARROYO COLOMA, M: Op. Cit; Págs. 181 a 182.

105 TEJERIZO LÓPEZ, J.M: "Fiscalidad y empleo de personas con discapacidad”; La dimensión social de la fiscalidad: discapacidad, tercer sector y mecenazgo; CERMI; 2017; Pág. 165

${ }^{106} \mathrm{https}$ ://www.autonomosyemprendedor.es/articulo/ayudas-y-subvenciones/fundacion-once-ayuda18000-euros-emprendedores-discapacidad/20181221144214018499.html
} 
Más difícil lo está tenido las discapacidades psíquicas al ser menos evidentes: tanto en el diagnóstico, verdaderamente complicado; como en la valoración, que se ha convertido en una tarea de especialistas; como en la aportación de ayudas efectivas para la inclusión de quienes manifiestan los TEA,S en la sociedad.

Es cierto que, una vez detectada la discapacidad, valorada la misma, el recorrido parece más fácil, aunque al analizar los beneficios y ayuda existentes es posible que muchas de ellas no se adecuen al perfil de ciertas personas en concreto. De ahí la dificultad para encontrar aquellas que nos puede favorecer, además de las genéricas que consisten en los beneficios fiscales que tienen un carácter objetivo y alcanza a todos los que tienen la valoración adecuada.

La enorme miscelánea existente en este campo, hace que sea difícil moverse en sus entresijos, de ahí la necesidad de crear personas versadas e interesadas en la materia, que además de saber, conozcan las estrategias para buscar entre los recursos disponibles y pongan su conocimiento al servicio de quienes no tienen la capacidad para ello.

Un aspecto importante en esta estrategia es la generación de organizaciones ${ }^{107}$ que aglutinen a los ciudadanos en defensa de los derechos de estas minorías, sin perjuicio de que se establezcan tantas asociaciones como sean necesarias para la interrelación, solución de problemas concreto y asesoramiento, no solo de los discapacitados, también de su entorno, que está necesitado de toda la información posible y que se agrupen en torno a instituciones mayores, con mayor capacidad de análisis y de orientación para las organizaciones más pequeñas ${ }^{108}$.

Este tipo de organizaciones son las que pueden aportar a los interesados, que principalmente van a ser los familiares de aquellas personas que manifiestan el TEA, la preocupación por estas situaciones, los conocimientos suficientes para que su interés por ayudar a estas personas sea eficaz. Pueden ser el cauce para generar una interlocución con las instituciones, de manera que se normativicen estos recursos de una forma más simple de lo que en la actualidad están y que se generen recursos, portales, guías... donde acudir para obtener este tipo de beneficios. Además de crean la necesaria conciencia social sobre una problemática, la de la diversidad, que afecta a un sector importante de la población y que, en el caso de la diversidad intelectual, supera el uno por ciento y a todo el entorno que se ve concernido. Lo que no son cifras desdeñables cuando se intenta buscar la forma de la inclusión en una sociedad que se siente más inclusiva. El conocimiento es el camino para superar las desigualdades y la difusión del mismo la fórmula para que cada vez seamos más quienes nos sintamos parte de la solución por saber que somos conocedores del problema.

En el futuro habrá que seguir creado nuevas formas de inclusión para quienes manifiesten alguna discapacidad en general y en especial para quienes las padecen de tipo psíquico, pues el objetivo debe ser ofrecer oportunidades a todos aquellos que pueden ser útiles a la sociedad y capacitar en la medida de lo posible, a los demás para que puedan llevar una vida más satisfactoria.

\footnotetext{
107 PEREZ BENO, LC (COORDINADOR): Sociedad Civil, inclusión social y sector fundacional en España. Estudio homenaje a Carlos Álvarez; CERMI; 2012; Obra colectiva que apuesta por este tipo de institución para aglutinar el estudio y defensa de las personas discapacitadas.

108 VARIOS AUTORES: “Tercer Sector, Fundaciones, Mecenazgo"; La dimensión social de la fiscalidad: discapacidad, tercer sector y mecenazgo; CERMI; 2017; págs. 199 a 403.
} 